\title{
A BIOGEOQUÍMICA DO RIO JI-PARANÁ, RONDÔNIA
}

\author{
NEI KAVAGUICHI LEITE
}

Dissertação apresentada à Escola Superior de Agricultura "Luiz de Queiroz”, Universidade de São Paulo, para obtenção do título de Mestre em Ecologia de Agroecossistemas.

P I R A C I C A B A

Estado de São Paulo - Brasil

Março - 2004 


\title{
A BIOGEOQUÍMICA DO RIO JI-PARANÁ, RONDÔNIA
}

\section{NEI KAVAGUICHI LEITE}

Licenciado em Matemática

Orientador: Prof. Dr. ALEX VLADIMIR KRUSCHE

\author{
Dissertação apresentada à Escola Superior de \\ Agricultura “Luiz de Queiroz”, Universidade de São \\ Paulo, para obtenção do título de Mestre em Ecologia \\ de Agroecossistemas.
}

P I R A C I C A B A

Estado de São Paulo - Brasil

Março - 2004 


\section{Dados Internacionais de Catalogação na Publicação (CIP) DIVISÃO DE BIBLIOTECA E DOCUMENTAÇÃO - ESALQ/USP}

Leite, Nei Kavaguichi

A biogeoquímica do Rio Ji-Paraná, Rondônia / Nei Kavaguichi Leite. - - Piracicaba, 2004

$44 \mathrm{p}$.

Dissertação (mestrado) - - Escola Superior de Agricultura Luiz de Queiroz, 2004.

Bibliografia.

1. Água 2. Bacia hidrográfica 3. Biogeoquímica 4. Cobertura do solo 5 . Ecologia aplicada 6. Impacto ambiental 7. Rios 8. Usos do solo I. Título

CDD 551.483

"Permitida a cópia total ou parcial deste documento, desde que citada a fonte - O autor" 


\section{Ofereço}

À minha família

Em especial, minha mãe Marta e minha irmã Marina

À memória do meu pai, José

E meu irmão, Rui, dedico 


\section{AGRADECIMENTOS}

Ao Prof. Dr. Alex Krusche, pela orientação, revisões e inúmeros incentivos para o desenvolvimento desta dissertação;

À Fundação de Amparo à Pesquisa do Estado de São Paulo (FAPESP) e todos os contribuintes do estado de São Paulo pela bolsa e reserva técnica concedida;

Ao Centro de Energia Nuclear na Agricultura (CENA), na pessoa do seu Diretor, Prof. Dr. Reynaldo Luiz Victória, por fornecer os meios necessários para a realização deste trabalho e pela confiança depositados à minha pessoa;

À ESALQ/USP, através do Programa de Pós-Graduação em Ecologia de Agroecossistemas pela oportunidade de aprendizado;

Aos Pesquisadores Dra. Vicky, Dr. Jean Pierre, Dr. Marcelo Bernardes, Dr. Jorge Moraes, pela co-orientação, revisões, sugestões apresentadas, além da amizade e apoio durante a realização desta dissertação;

À Universidade Federal de Rondônia, e todo o seu quadro de professores, pelo apoio prestado;

À Marcos Alexandre Bolson e Sérgio Gouveia Neto, pelas contribuições nas atividades de campo;

Ao laboratório de Ecologia Isotópica e todos os seus funcionários: Fabiana, Neusa, Toninha, Edmar, Geraldo pelo apoio logístico;

À todos os amigos dos Laboratórios de Ecologia Isotópica e Geoprocessamento, pelo excelente convívio durante o período em que estive em Piracicaba;

Aos estagiários Xanda, Rodrigo, Patrícia, Camila, Gustavo, Andréia; 
Às Repúblicas Antro (Hétero, Rauni, Bandido, Jah, Maezono, Bérni, Da Paz, Pela Ordem e Ultra-Leve) e Blue House (Pelé, Sandal, CPI, Frávião, Denis, Ricardo, Véio, Mura, Presidente e Fininho), pelo companheirismo e apoio;

Finalmente, desculpando-me por alguns esquecimentos, agradeço a tantos os demais colegas e amigos que colaboraram direta ou indiretamente para que este trabalho fosse realizado. 


\section{SUMÁRIO}

Página

LISTA DE FIGURAS ................................................... viii

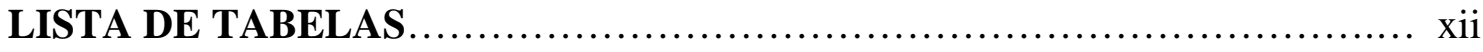

LISTA DE ABREVIATURAS E SÍMBOLOS.................................................. xiii

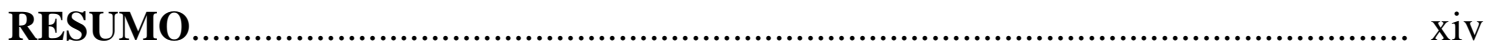

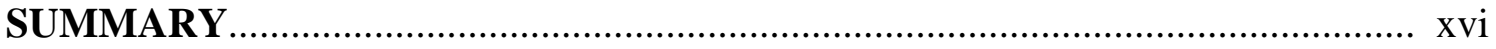

1 INTRODUÇÃ

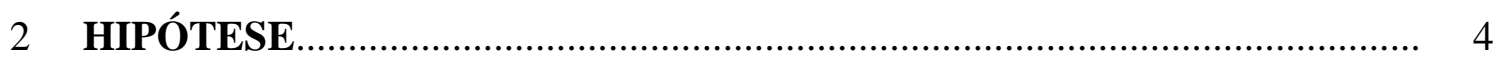

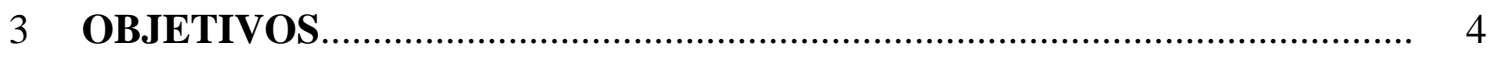

4 MATERIAL E MÉTODOS................................................................ 5

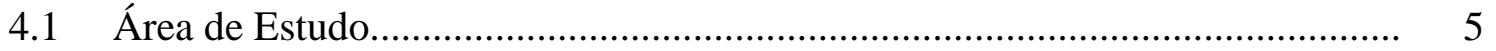

4.2 Métodos Amostrais e Medidas de Campo..................................................... 11

4.3 Métodos Analíticos.................................................................................. 12

4.3.1 Íons Maiores e Nutrientes (N e P) ..................................................... 12

4.3.2 Carbono Orgânico e Inorgânico Dissolvidos............................................. 12

4.3.3 Sedimentos em Suspensão.............................................................. 14

4.4 Análises Estatísticas............................................................................... 14 


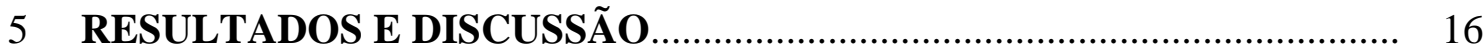

5.1 Comportamento Hidrológico............................................................. 16

5.2 Características Gerais: Diagramas Ternários............................................... 16

5.3 Variações Espaciais........................................................................ 21

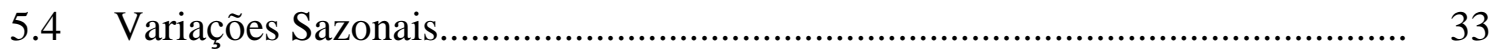

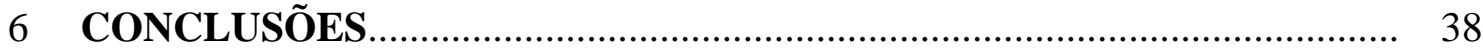

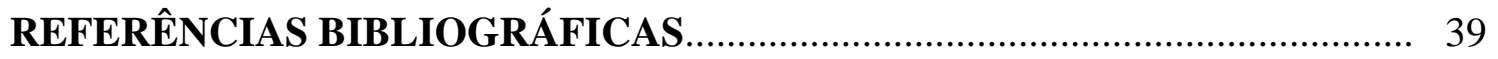




\section{LISTA DE FIGURAS}

Página

1 Mapa da bacia de drenagem do rio Ji-Paraná com a localização dos 14

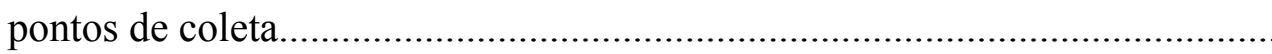

2 Uso da terra na bacia do rio Ji-Paraná, conforme observado em imagens de Julho e Setembro de 1999 obtidas pelo satélite Landsat-7, ETM+. Dados obtidos do Tropical Rainforest West Inventory.

3 Mapa de unidades de solos da bacia do rio Ji-Paraná (EMBRAPA, 1983), modificado para novo sistema de classificação de solos (EMBRAPA, 1999)..

4 Relação entre o somatório de cátions $\left(\mathrm{TZ}^{+}\right)$e ânions $\left(\mathrm{TZ}^{-}\right)$nas amostras de água dos rios da bacia do rio Ji-Paraná (valores em

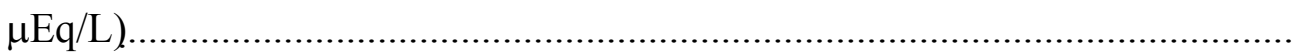

5 Descargas diárias, em $\mathrm{m}^{3} \cdot \mathrm{s}^{-1}$, do rio Ji-Paraná, na cidade de Ji-Paraná, durante o período de 1999 a 2001. As setas indicam os meses em que foram efetuadas as coletas de amostras. 
6 Descargas diárias do rio Ji-Paraná, em $\mathrm{m}^{3} \cdot \mathrm{s}^{-1}$, no ponto próximo da cidade de Tabajara (JIP-4). A curva contínua (preta) corresponde à média histórica (1985-2001) e a descontínua (vermelha) à vazão no período deste estudo......

7 Diagrama ternário elaborado a partir das concentrações dos cátions maiores nas amostras de água dos rios da bacia do Ji-Paraná, onde A corresponde aos pontos que apresentaram predominância de $\mathrm{Ca}^{2+}$ e $\mathrm{B}$, predominância de $\mathrm{Na}^{+}$ $+\mathrm{K}^{+}$

8 Diagrama ternário elaborado a partir das concentrações dos ânions maiores para as amostras de água dos rios da bacia do Ji-Paraná.

9 Condutividade Elétrica média nas águas dos pontos amostrados (valores em $\mu$ S.cm $\left.{ }^{-1}\right)$.

10 Concentração média dos cátions maiores nas águas dos rios da bacia do Ji-Paraná (valores em $\mu \mathrm{M}$ ).

11 Concentração média dos ânions maiores nas águas dos rios da bacia do JiParaná (valores em $\mu \mathrm{M}$ ).

12 Valores médios de $\mathrm{pH}$ nas águas dos rios da bacia do JiParaná.

13 Concentração de Sedimentos Totais em Suspensão nas águas dos rios da bacia do Ji-Paraná (valores em mg. $\mathrm{L}^{-1}$ ). 
14 Concentração de Carbono Orgânico Dissolvido nas águas dos rios da

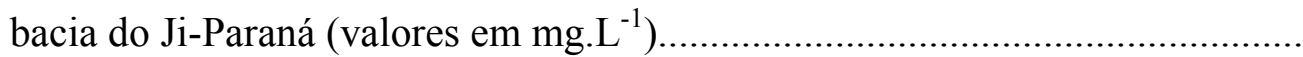

15 Relação entre Carbono Orgânico Dissolvido e Sedimentos Totais em Suspensão (as concentrações estão divididas pela área de cada sub-bacia).......

16 Variação espacial das concentrações de $\mathrm{NO}_{3}{ }^{-}$nas águas dos rios da bacia do Ji-Paraná (valores em $\mu \mathrm{M}$ )

17 Variação espacial das concentrações de $\mathrm{NO}_{2}{ }^{-}$nas águas dos rios da bacia do Ji-Paraná (valores em $\mu \mathrm{M}$ )

18 Variação espacial das concentrações de $\mathrm{NH}_{4}{ }^{+}$nas águas dos rios da bacia do Ji-Paraná (valores em $\mu \mathrm{M}$ )

19 Variação espacial das concentrações de $\mathrm{PO}_{4}{ }^{3-}$ nas águas dos rios da bacia do Ji-Paraná (valores em $\mu \mathrm{M}$ )

20 Relação entre Vazão e Condutividade Elétrica para os rios mais empobrecidos em íons dissolvidos na bacia do Ji-Paraná.

21 Relação entre Vazão e Condutividade Elétrica para os rios mais enriquecidos em íons dissolvidos na bacia do Ji-Paraná.

22 Variação temporal das concentrações de Sedimentos Totais em Suspensão nas águas dos rios da bacia do Ji-Paraná (valores em mg. $\mathrm{L}^{-1}$ ). 
23 Variação sazonal do Nitrogênio Inorgânico Dissolvido nas águas dos rios

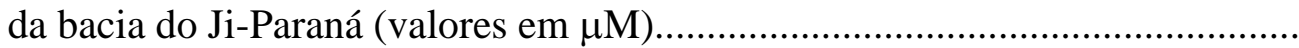

24 Variação temporal das concentrações de $\mathrm{PO}_{4}{ }^{3-}$ nas águas dos rios da bacia

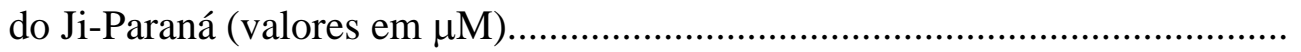




\section{LISTA DE TABELAS}

Página

1 Identificação dos locais de amostragem na bacia do rio JiParaná......

2 Locais amostrados, número de coletas (n) e valores médios de $\mathrm{pH}$, condutividade elétrica (Cond.), temperatura (Temp.) e sedimentos totais em suspensão (STS) nos pontos amostrados na bacia do rio JiParaná

3 Composição química dos principais elementos dissolvidos (íons maiores e nutrientes) do rio Ji-Paraná e seus principais tributários (Valores expressos em $\mu \mathrm{M})$ 


\title{
LISTA DE ABREVIATURAS E SÍMBOLOS
}

\author{
ANA - Agência Nacional de Águas \\ ANOVA - Análise de Variância \\ $\mathrm{Ca}^{2+}$ - Cálcio \\ $\mathbf{C O}_{2}$ - Dióxido de Carbono \\ CETC - Capacidade Efetiva de Troca de Cátions \\ CID - Carbono Inorgânico Dissolvido \\ $\mathrm{Cl}^{-}$- Cloreto \\ $\mathrm{CO}_{3}{ }^{-}$- Carbonato \\ COD - Carbono Orgânico Dissolvido \\ $\mathrm{HCO}_{3}{ }^{-}$- Bicarbonato \\ $\mathbf{H g C l}_{2}$ - Cloreto de Mercúrio \\ INPA - Instituto Nacional de Pesquisas da Amazônia \\ $\mathbf{K}^{+}$- Potássio \\ $\mathbf{M g}^{2+}$ - Magnésio \\ $\mathrm{Na}^{+}$- Sódio \\ $\mathbf{N H}_{4}^{+}$- Amônio \\ NID - Nitrogênio Inorgânico Dissolvido \\ $\mathrm{NO}_{2}^{-}$- Nitrito \\ $\mathrm{NO}_{3}{ }^{-}$- Nitrato \\ OD - Oxigênio Dissolvido \\ pH - Potencial Hidrogênionico \\ $\mathbf{P O}_{4}{ }^{3-}$ - Fósforo Dissolvido Solúvel \\ Q - Descarga \\ RO - Rondônia \\ $\mathrm{SO}_{4}{ }^{2-}$ - Sulfato \\ STS - Sedimentos Totais em Suspensão \\ $\mathbf{T Z}^{+}$- Somatório de Cátions \\ TZ - Somatório de Ânions
}




\title{
A BIOGEOQUÍMICA DO RIO JI-PARANÁ, RONDÔNIA.
}

\author{
Autor: NEI KAVAGUICHI LEITE \\ Orientador: Prof. Dr. ALEX VLADIMIR KRUSCHE
}

\section{RESUMO}

As mudanças no uso da terra que ocorreram no estado de Rondônia nas últimas décadas transformaram a paisagem da região. Especialmente ao longo da BR-364, o que antes era constituído quase que exclusivamente por florestas, hoje apresenta extensas áreas cobertas por pastagens, com impactos ainda desconhecidos no ambiente aquático. O presente trabalho procurou identificar a importância relativa das características naturais e antrópicas da bacia de drenagem na biogeoquímica das águas do rio Ji-Paraná e seus principais tributários, levando-se em consideração que a composição química de um rio reflete os processos que ocorrem em sua bacia de drenagem. Para isto, foi utilizada uma abordagem comparativa, na qual se avaliaram as diferenças entre sistemas com distintos usos e cobertura do solo, além das variações sazonais ao longo do período de estudo (1999-2002). Em relação às variações espaciais, as menores concentrações de analitos foram encontradas nos rios drenando áreas com solos mais arenosos e menor fertilidade, enquanto as maiores foram encontradas nos rios localizados na região central da bacia, com os solos mais argilosos e férteis. Em relação às variações temporais, observou-se que os rios em cujas bacias predominam florestas apresentaram correlações positivas entre a descarga e as concentrações de íons, enquanto que, para os rios em cujas bacias predominam pastagens, apesar de apresentarem correlação, esta foi negativa. Estes resultados poderiam indicar um controle da química destas águas apenas 
por processos naturais. Entretanto, analisando as variações dos nutrientes $\mathrm{C}, \mathrm{N}$ e $\mathrm{P}$, observou-se que a presença humana já começa a influenciar a biogeoquímica destes rios. 


\title{
THE BIOGEOCHEMISTRY OF JI-PARANÁ RIVER, RONDONIA
}

\author{
Author: NEI KAVAGUICHI LEITE \\ Adviser: Prof. Dr. ALEX VLADIMIR KRUSCHE
}

\section{SUMMARY}

Land use changes that occurred in the state of Rondonia in the last decades transformed the landscape of this region. Mainly along the road BR-364, what was almost all forest before is now covered with extensive pastures, with impacts in the aquatic systems that are still not known. This dissertation aims the identification of the relative importance of the natural and anthropogenic characteristics of the basin in the biogeochemistry of the Ji-Paraná river and its main tributaries, assuming that the chemistry of river waters reflects what happens in its basin. To achieve that, a comparative approach was used, in which differences between systems with distinct soils and land use/cover were analyzed, as well as seasonal variations during the period of this study (1999-2002). Regarding spatial variations, the lowest concentrations of ions were found in rivers draining areas with sandy and less fertile soils, whereas the highest ones were found in rivers located in the central part of the basin, draining soils with higher clay content and more fertile. In relation to seasonal variations, it was observed that rivers draining basins in which forests predominate show positive correlations between discharge and ionic content, while rivers draining basins with large areas of pastures, showed inverse correlations between discharge and concentrations of ions. These results indicate that the natural characteristics of these basins might be the main controlling factor of river biogeochemistry. However, variations in nutrient 
concentrations, such as $\mathrm{C}, \mathrm{N}$ and $\mathrm{P}$, also indicate that human influences are already present in these systems. 


\section{INTRODUÇÃO}

Compreendendo uma área de aproximadamente 5 milhões de quilômetros quadrados (60\% do território brasileiro), a Amazônia representa um dos principais ecossistemas do planeta, em virtude da vasta biodiversidade (Fearnside, 1999), extensas regiões cobertas por floresta tropical úmida ${ }^{1}$ (Eden, 1978; Herrera et al., 1978; Hiraoka, 1982; Bush, 1996), grande variedade de solos (Krishnaswamy et al,. 2002; Richter et al., 1991) e, principalmente, por englobar o rio Amazonas e seus inúmeros tributários, que formam a maior rede de drenagem do mundo (Gibbs, 1972; Sioli, 1984; Richey et al., 1990).

Segundo Victória et al. (2000), o rio Amazonas constitui uma bacia hidrográfica clássica, com uma vasta planície central, margeada por uma região caracterizada como terra firme, e cujo canal principal recebe o aporte de uma série de tributários de variadas extensões, apresentando distintas características físicas e químicas.

A partir da década de 60, esta bacia passou por várias investigações, iniciadas com a estimativa da vazão no canal principal do rio Amazonas (Oltman, 1968), e seguida por diversos modelos de classificação, baseados em características físicas e químicas comuns, que procuravam identificar os principais fatores ambientais controladores da química destas águas (Gibbs, 1970; Sioli, 1975; Stallard, 1983).

Entretanto, estes modelos não levam em conta as alterações promovidas pelo homem, que passou a ser um importante agente na atual estrutura da paisagem deste ecossistema, principalmente através de práticas arcaicas de manejo da terra para fins agropecuários (Walker \& Homma, 1996). Dentro deste contexto, a

\footnotetext{
${ }^{1}$ Cerca de 3,5 milhões de quilômetros quadrados (Diegues, 1999)
} 
Bacia Amazônica deixou de ser um sistema intocado e composto majoritariamente por florestas tropicais úmidas, para se tornar uma região modificada pelo desmatamento (Richey, 1997).

Somente no território brasileiro, cerca de 15\% das áreas antes cobertas por florestas (600 mil km²) deram lugar a outros usos (Davidson, 2003), decorrentes principalmente do rápido desenvolvimento ocorrido a partir da década de 60. Este foi motivado, principalmente, pela construção de rodovias (Belém-Brasília, Transamazônica, Cuiabá - Porto Velho), combinada com os incentivos do governo, na forma de planos de integração e distribuição de terras, entre outros subsídios (Salati et al., 1989; Pedlowski et al., 1997; Lambin et al., 2001). O estado de Rondônia constitui um importante exemplo destes processos, onde, em apenas 22 anos $^{2}$, 25\% do território foi desmatado, representando a terceira maior taxa de desmatamento da Amazônia Brasileira (BRASIL, 2002).

Estas perturbações do ambiente natural representam um sério risco para sua sustentabilidade, podendo influenciar na ciclagem biogeoquímica de elementos (Melillo et al., 1996; Downing et al., 1999; Herpin et al., 2002), distribuição da matéria orgânica (Richey et al., 1997) e de espécies animais e vegetais (Dale et al., 1994; Fearnside, 1999; Putz et al., 2001), propriedades físicas e químicas do solo (Reiners et al., 1994; Neill et al., 1995; Mcgrath et al., 2001), bem como o clima (Gash et al., 1996; Tinker et al., 1996).

Entretanto, tais conseqüências para ambientes aquáticos tropicais são ainda baseadas em resultados de estudos muitas vezes realizados em ambientes com climas e condições ambientais totalmente diferentes dos encontrados na região Amazônica (Likens \& Bormann, 1995; Collins \& Jenkins, 1996; Pekarova \& Pekar, 1996; Rhodes et al., 2001). Estudos para avaliar os efeitos das alterações do uso e cobertura da terra na biogeoquímica de rios localizados em bacias de drenagem dos trópicos são restritos a poucos exemplos (Williams, 1997; Biggs, 2002; Ballester et al. 2003; Krusche et al., no prelo).

${ }^{2} 4.200 \mathrm{~km}^{2}$ desmatados em 1978 e $58.143 \mathrm{~km}^{2}$ em 2000 (INPE, 2000). 
O principal mecanismo utilizado nestas alterações do ambiente natural na Amazônia tem sido o corte e queima, que consiste inicialmente na abertura de clareiras removendo as principais espécies de valor comercial, deixando apenas alguns resíduos vegetais que, após estarem secos, são queimados no período anterior às maiores precipitações (Kleinman et al., 1995).

Em estudo publicado na década de 60, Nye e Greenland, propuseram que este manejo disponibiliza cinzas enriquecidas em nutrientes, que seriam responsáveis pelo aparente aumento na fertilidade dos solos ${ }^{3}$ (Uhl \& Jordan, 1984; Nye e Greenland, 1960 apud Giardina et al., 2000). Segundo estes autores, a queima dos resíduos vegetais gera cinzas enriquecidas em cátions no período seguinte à ação do fogo, que são depositadas na superfície dos solos e posteriormente incorporadas neste compartimento a partir da ação da chuva e da prática de manejo empregada. Esta adição pode ser benéfica para solos ácidos, visto que, a incorporação destas cinzas promove aumento no $\mathrm{pH}$, podendo influenciar na fertilidade através de uma maior retenção de nutrientes no perfil do solo (Giardina et al., 2000).

Alguns estudos efetuados em pequenos rios de $1^{\circ}$ ordem apontam que tais mudanças na dinâmica de nutrientes do solo podem alterar as características químicas do ecossistema aquático. Markewitz et al, (2001) encontraram as maiores concentrações de íons dissolvidos no período de maiores vazões, em igarapés localizados na região de Paragominas-PA, atribuindo este fato à erosão superficial e lixiviação dos cátions presentes nas camadas superficiais do solo. O mesmo foi observado por Williams e Melack, em estudo realizado no Lago Calado, próximo da cidade de Manaus, onde foi encontrada uma forte correlação entre o desmatamento e o balanço hidroquímico dos rios, expresso através da redução na evapotranspiração com subseqüente aumento na descarga e transporte de solutos (Williams \& Melack, 1997).

Dentro deste contexto, foi escolhida a bacia de meso-escala do rio Ji-Paraná, localizada no estado de Rondônia, procurando fornecer maiores subsídios para a compreensão das influências naturais e antropogênicas na biogeoquímica das águas de

\footnotetext{
${ }^{3}$ Expresso através do aumento de cátions trocáveis do solo e pH.
} 
rios da Amazônia, além de investigar se estes efeitos observados em rios menores se repetem com o aumento da escala.

\section{HIPÓTESE}

As mudanças no uso da terra nos últimos vinte anos no Estado de Rondônia foram de uma intensidade tal que alterações na química das águas superficiais devem ser perceptíveis naqueles sistemas onde hoje predominam pastagens, em relação àqueles onde ainda existe a vegetação de floresta original.

\section{OBJETIVOS}

-Analisar os padrões espaço-temporais da química das águas superficiais dos principais tributários e canal principal do rio Ji-Paraná, Rondônia;

- Correlacionar as distintas composições químicas das águas destes rios com características naturais e os usos da terra nas diferentes sub-bacias estudadas. 


\section{MATERIAL E MÉTODOS}

\section{1 Área de Estudo}

O rio Ji-Paraná atravessa o estado de Rondônia de sudeste a noroeste. Sua bacia de drenagem está localizada entre os paralelos 802'32'’ e 1259'50'’ de latitude sul e os meridianos 6004'56'’ e 6316’30'” de longitude oeste, englobando uma área de aproximadamente $75.400 \mathrm{~km}^{2}$ (Figura 1). Este corpo d’água é formado pela confluência, na proximidade da cidade de Pimenta Bueno, dos rios Pimenta Bueno e Comemoração, percorrendo um setor com baixo impacto antropogênico em suas cabeceiras e com maior grau de perturbação na região central da bacia (Figura 1, Tabela 1). No seu trecho médio, o rio Ji-Paraná drena o setor mais impactado da bacia, onde recebe os tributários Rolim de Moura, Urupá e Jarú. Mais à jusante a vegetação predominante consiste de floresta nativa e o rio recebe ainda, o aporte de outros dois importantes afluentes, Machadinho e Preto. Estas alterações no uso da terra foram separadas em quatro categorias de impacto (Tabela 1), classificadas em função do percentual da área da subbacia coberta com pastagem (Ballester et al., 2003; Krusche et al., no prelo), onde:

- Impacto Baixo - 0 e 15\% da área da sub-bacia que contém pastagens;

- Impacto Médio - 15 a 30\%;

- Impacto Alto - 30 a 50\%, e

- Impacto Muito Alto - 50 a $75 \%$.

Para abranger os distintos usos da terra encontrados nesta bacia (Figura 2), foram definidos 14 pontos de coleta (Figura 1), sendo cinco localizados no canal principal do 


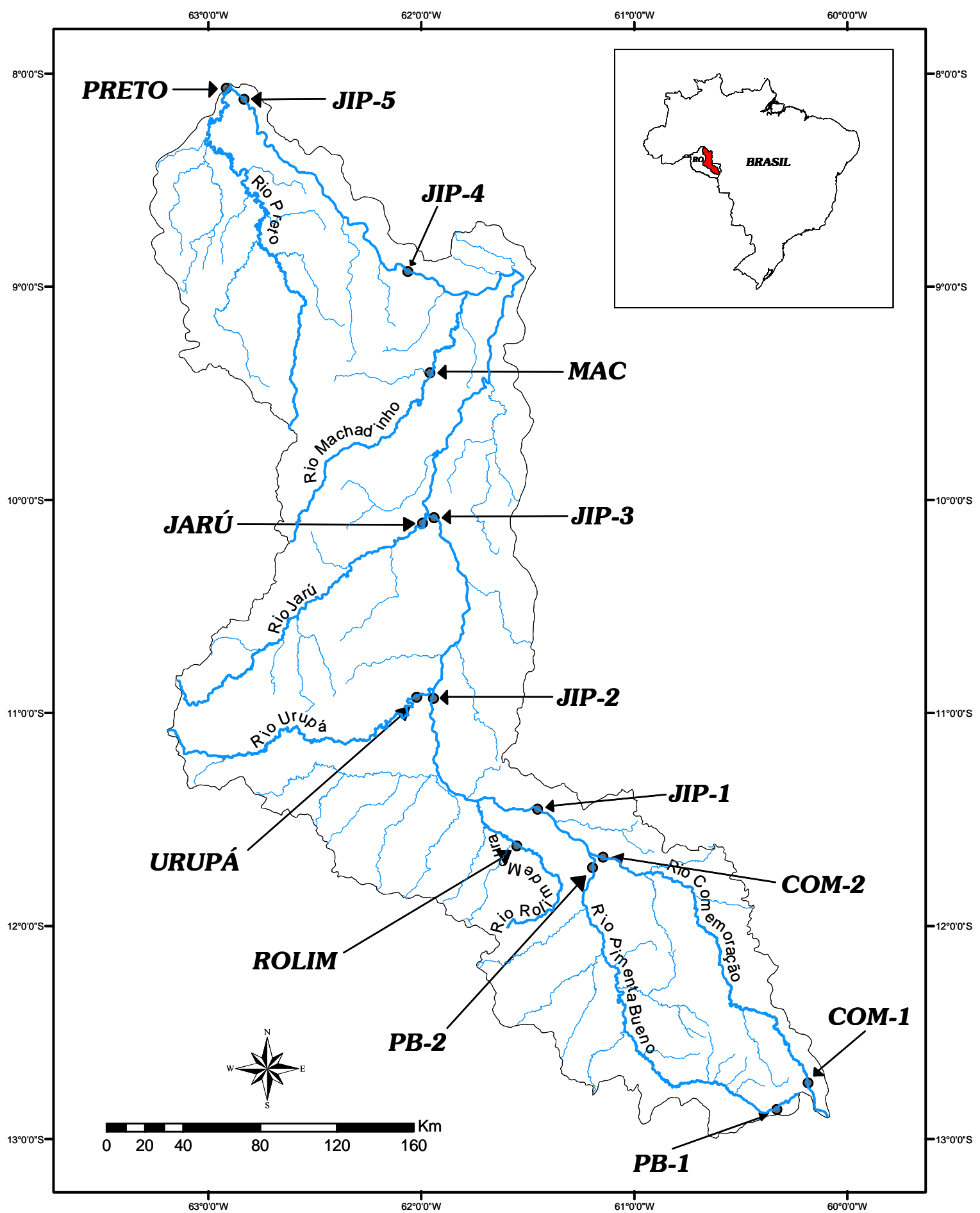

Figura 1 - Mapa da bacia de drenagem do rio Ji-Paraná com a localização dos 14 pontos de coleta 

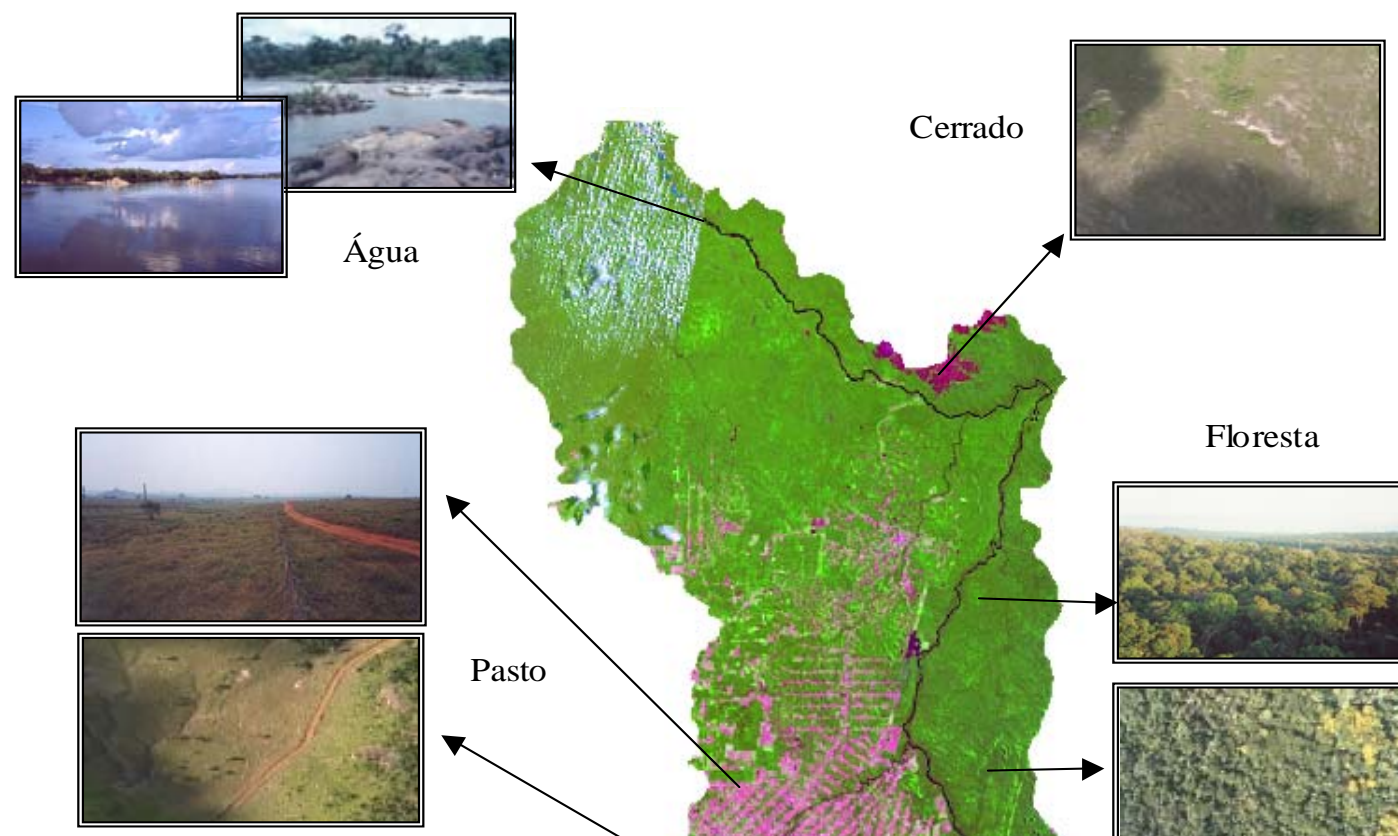

Floresta

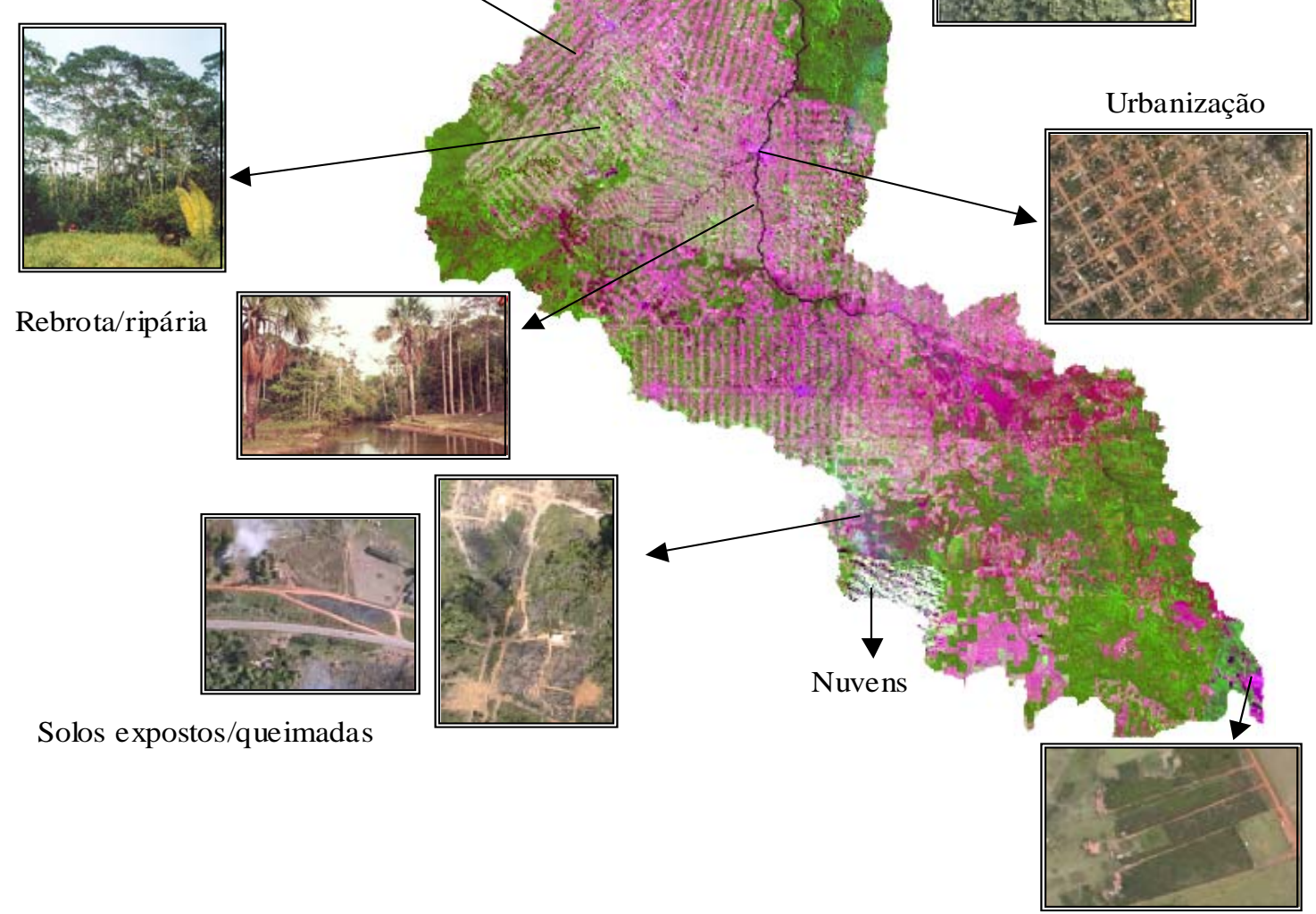

Culturas anuais

Figura 2 - Uso da terra na bacia do rio Ji-Paraná, conforme observado em imagens de Julho e Setembro de 1999 obtidas pelo satélite Landsat-7, ETM+. Dados obtidos do Tropical Rainforest West Inventory 
Tabela 1. Identificação dos locais de amostragem na bacia do rio Ji-Paraná

\begin{tabular}{cccc}
\hline Ponto & Rio & Local & Grau de Alteração do Uso do Solo \\
\hline COM-1 & Comemoração & Vilhena & Baixo \\
COM-2 & Comemoração & Pimenta Bueno & Médio \\
PB-1 & Pimenta Bueno & Vilhena & Baixo \\
PB-2 & Pimenta Bueno & Pimenta Bueno & Médio \\
JIP-1 & Ji-Paraná & Cacoal & Alto \\
ROLIM & Rolim de Moura & Cacoal & Muito Alto \\
JIP-2 & Ji-Paraná & Ji-Paraná & Muito Alto \\
URUPÁ & Urupá & Ji-Paraná & Muito Alto \\
JIP-3 & Ji-Paraná & Rebio do Jarú & Alto \\
JARÚ & Jarú & Rebio do Jarú & Alto \\
MAC & Machadinho & Machadinho d’Oeste & Baixo \\
JIP-4 & Ji-Paraná & Tabajara & Baixo \\
JIP-5 & Ji-Paraná & Calama & Baixo \\
PRETO & Preto & Calama & Baixo \\
\hline
\end{tabular}

rio Ji-Paraná: JIP-1, na cidade de Cacoal; JIP-2, na cidade de Ji-Paraná; JIP-3, próximo à Reserva Biológica do Jarú; JIP-4, na cidade de Tabajara e; JIP-5 próximo da cidade de Calama. Nos seus principais tributários os locais de amostragem foram: Comemoração (COM-1 e COM-2), Pimenta Bueno (PB-1 e PB-2), Rolim de Moura (ROLIM), Urupá (URUPA), Jarú (JARU), Machadinho d’Oeste (MAC) e Preto (PRETO).

As coletas foram realizadas trimestralmente, entre maio de 1999 a abril de 2002, totalizando nove amostragens, com exceção dos pontos JIP-5 e Rolim, com 8 coletas e o Preto com 6, devido à problemas logísticos no período em que as coletas foram conduzidas.

A descarga média anual dos rios Comemoração e Pimenta Bueno nas proximidades da confluência são de 150 e $223 \mathrm{~m}^{3} . \mathrm{s}^{-1}$, respectivamente. No rio Ji-Paraná, este valor aumenta para $1.520 \mathrm{~m}^{3} \cdot \mathrm{s}^{-1}$ na última estação fluviométrica da Agência Nacional de Águas (ANA) na bacia, situada à jusante da cidade de Tabajara, no ponto JIP-4.

O clima da região, de acordo com a classificação de Köppen, é considerado tropical chuvoso, dividido entre os grupos Am, mais ao norte do estado e Aw, mais ao sul, e apresentando um regime pluviométrico com média anual de $2.200 \mathrm{~mm}$ (Bastos \& 
Diniz, 1982). As maiores precipitações ocorrem entre os meses de Dezembro e Março, enquanto o período de estiagem se estende de Julho a Setembro (Rondônia, 2002).

Os solos da área de estudo apresentam uma distribuição espacial bastante heterogênea (Figura 3), com áreas onde predominam solos muito arenosos e pobres em cátions e "manchas” isoladas de solos com maiores teores de argila e mais ricos em cátions.

Os tipos de solos mais representativos são os Latossolos e Argissolos, com 47\% e 24\%, respectivamente, da área total da bacia de drenagem, com o restante se distribuindo entre os Neossolos Quartzarênicos (14\%), Nitossolos (13\%) e Cambissolos (2\%). Segundo Ballester et al. (2003) estes solos apresentam uma composição média de 57,9\% de areia, 32,8\% de argila e 9,3\% de silte nos primeiros 15 a $20 \mathrm{~cm}$.

Nas cabeceiras dos rios Pimenta Bueno e Comemoração, e em praticamente toda a área das sub-bacias dos rios Preto e Machadinho, encontram-se os solos mais pobres da bacia, ao passo que nas bacias dos rios Rolim de Moura, Urupá e Jarú localizam-se os solos mais ricos. Nas regiões centrais do Ji-Paraná e do Pimenta Bueno também são observadas “manchas” de solos mais ricos (Ballester et al., 2003).

Tais características foram determinantes para o processo de colonização do estado de Rondônia. Apesar de muitas áreas terem sua cobertura florestal original substituída por pastagens, somente nos setores da bacia onde os solos são mais ricos as mesmas foram mantidas até hoje (Ballester et al., 2003; Krusche et al., no prelo).

Portanto, existe uma estreita relação entre a fertilidade (em termos do conteúdo de bases) dos solos e a presença de pastagens, que é a mais importante alteração antropogênica da região (Figuras 2 e 3).

De acordo com o Mapa Geológico do Estado de Rondônia (Scandolara et al., 1998), a área de estudo compreende várias unidades litológicas. No rio Comemoração e na cabeceira do Pimenta Bueno observa-se um substrato sedimentar (arenitos, argilitos e siltitos), enquanto no setor mais à jusante deste último, podem ser observados “afloramentos” rochosos mais recentes (basaltos, gabros), dentro da Formação Basalto Anari. Na região central da bacia, os tributários Rolim de Moura e Jarú drenam rochas metamórficas (gnaisses, kinzigitos), enquanto no rio Urupá foi 


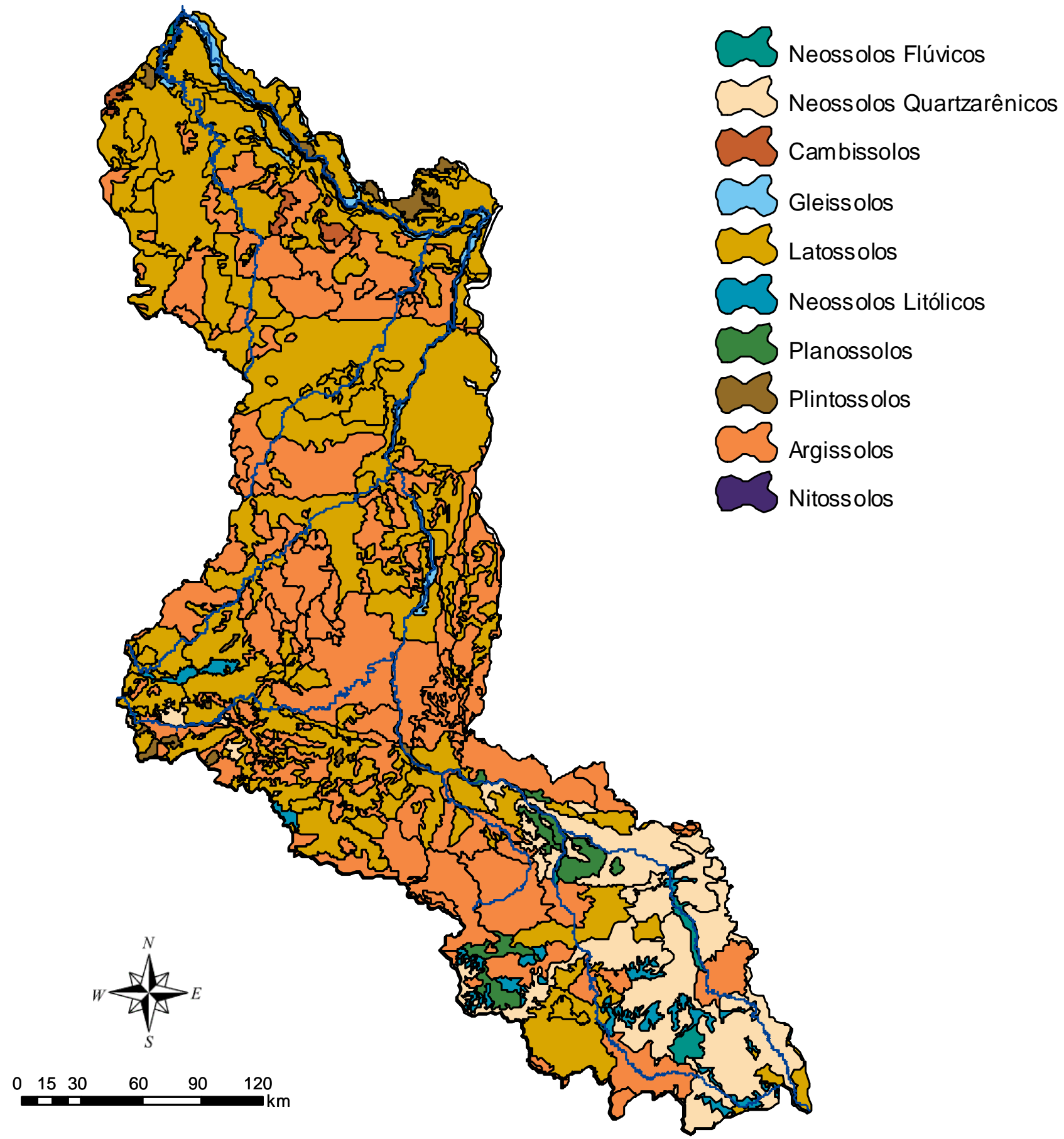

Figura 3 - Mapa de unidades de solos da bacia do rio Ji-Paraná (EMBRAPA, 1983), modificado para novo sistema de classificação de solos (EMBRAPA, 1999) 
encontrada uma mistura de rochas de origem vulcânica e sedimentar. Os dois últimos afluentes mais importantes, Machadinho e Preto, apresentaram rochas sedimentares associadas a canais fluviais, decorrentes da deposição e precipitação de sedimentos em suspensão.

\subsection{Métodos Amostrais e Medidas de Campo}

Amostras de água foram obtidas a partir da imersão de uma garrafa de Niskin de 10 litros no meio do canal dos rios, a 60\% da profundidade total (Hauer, F. R. \& Lamberti, G. A, 1996), o material assim coletado foi dividido nas seguintes alíquotas:

a) alíquota de $60 \mathrm{ml}$, filtrada com um filtro de nitrato de celulose (porosidade nominal de 0,47 $\mu \mathrm{m}$ ), acondicionada em frasco de polietileno de alta densidade e preservada com 6 mg de thymol, para a determinação das concentrações de íons;

b) alíquota de $25 \mathrm{ml}$, filtrada com um filtro calcinado de fibra de vidro (Whatman tipo GF/F), com porosidade nominal de 0,7 $\mu \mathrm{m}$, acondicionada em frasco de vidro précalcinado, e preservada com $\mathrm{HgCl}_{2}$ a uma concentração final de $\mathrm{Hg}$ de $300 \mu \mathrm{M}$, para determinar a concentração de carbono orgânico dissolvido;

c) uma alíquota de 2 litros, acondicionada em frasco de polietileno, preservada com $\mathrm{HgCl}_{2}$ como acima, para determinar as concentrações de sedimentos em suspensão.

Após a retirada destas alíquotas, na mesma garrafa de Niskin foram determinadas as concentrações de oxigênio dissolvido e temperatura da água, com medidor portátil YSI, modelo 58, o pH, com medidor portátil Orion, Modelo 250A e a condutividade elétrica, com um condutivímetro Amber Science, Modelo 2052. 


\subsection{Métodos Analíticos}

\subsection{1 Íons Maiores e Nutrientes ( $\mathrm{N}$ e P)}

As concentrações dos cátions sódio, cálcio, magnésio, potássio e amônio, e dos ânions cloreto, sulfato, nitrato e nitrito foram determinadas através da técnica de cromatografia líquida com supressão de íons, empregando um equipamento Dionex DX500.

O método consiste na injeção da amostra em uma fase móvel, passando por uma coluna de troca iônica (fase estacionária), com sua detecção sendo obtida por condutividade elétrica. As colunas analíticas empregadas foram IonPac AS14HC (4mm) e CS12A (4mm) (Dionex, 2000), para os ânions e cátions, respectivamente. As concentrações foram calculadas por comparação com padrões externos.

Com o intuito de verificar a qualidade destas análises químicas, foi avaliada se a neutralidade de cargas foi obtida, comparando o somatório das cargas positivas com as negativas (Figura 4). Esta correlação apresentou um valor de $r^{2}=0.87$ e nível de significância de $\mathrm{p}<0.001$, indicando que as análises apresentaram qualidade aceitável.

\subsubsection{Carbono Orgânico e Inorgânico Dissolvidos}

Para determinar as concentrações de carbono orgânico dissolvido (COD) e carbono inorgânico dissolvido (CID) foi utilizado um equipamento da marca Shimadzu, modelo TOC-5000A (“Total Organic Carbon Analyser”), com detecção na forma de $\mathrm{CO}_{2}$ em um analisador de gases não dispersivo com absorbância no comprimento de onda infra-vermelho. O equipamento possui duas vias de análise, sendo uma para a fração orgânica e outra para a inorgânica:

a) Análise da fração orgânica: uma alíquota da amostra foi previamente acidificada até $\mathrm{pH}$ 1,0, borbulhada com ar sintético para retirar a fração inorgânica do carbono (convertida a $\mathrm{CO}_{2}$ pela acidificação), e então injetada no 


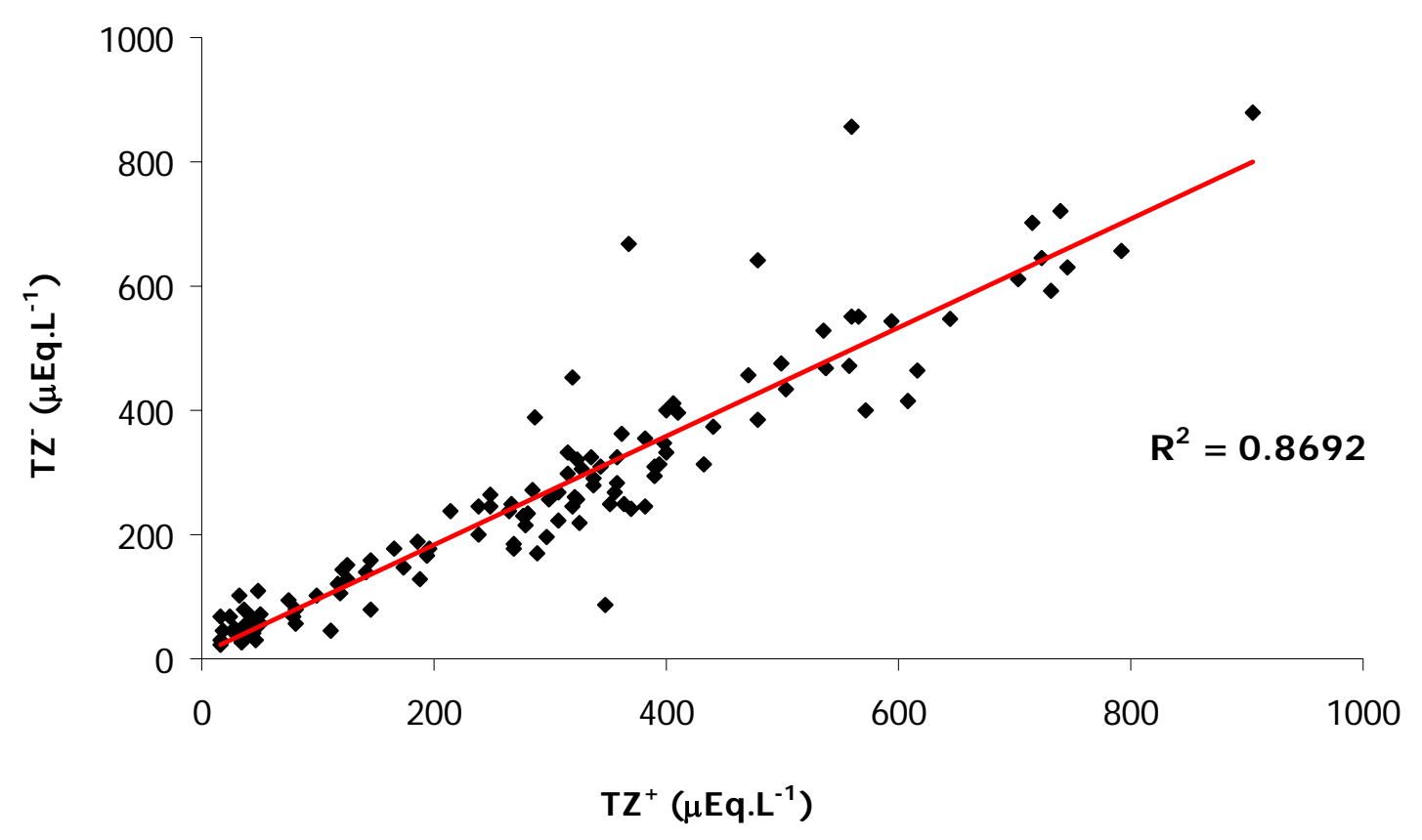

Figura 4 - Relação entre o somatório de cátions $\left(\mathrm{TZ}^{+}\right)$e ânions (TZ) nas amostras de água dos rios da bacia do rio Ji-Paraná (valores em $\mu \mathrm{Eq} / \mathrm{L}$ )

equipamento, onde foi queimada à $680^{\circ} \mathrm{C}$. $\mathrm{O}$ gás produzido pela queima foi então carreado por um fluxo de ar sintético, passando por uma coluna de resfriamento, um desumidificador eletrônico, um removedor de gases halogenados e uma membrana de filtro, até chegar ao detector, onde o $\mathrm{CO}_{2}$ produzido pela queima é quantificado. As concentrações são determinadas por comparação com padrões externos.

b) Análise da fração inorgânica: no caso do carbono inorgânico dissolvido não há pré-acidificação ou queima. A amostra é injetada diretamente e carreada para dentro de um recipiente com ácido, onde os carbonatos passam à forma de $\mathrm{CO}_{2}$, que é carreado para o detector seguindo o mesmo procedimento citado anteriormente para o COD. As concentrações são determinadas conforme descrito acima.

As concentrações de bicarbonato $\left(\mathrm{HCO}_{3}{ }^{-}\right)$e carbonato $\left(\mathrm{CO}_{3}{ }^{2-}\right)$ foram calculadas a partir das concentrações de carbono inorgânico dissolvido total, do $\mathrm{pH}$ e das 
temperaturas, empregando as equações de equilíbrio termodinâmico (Stumm \& Morgan, 1996).

\subsubsection{Sedimentos em Suspensão}

As concentrações de sedimentos em suspensão foram determinadas por gravimetria. Para determinar as concentrações de sedimentos em suspensão grossos, uma alíquota da amostra, ainda em campo, foi peneirada através de uma malha com porosidade nominal de $63 \mu \mathrm{m}$. O material retido na mesma foi recolhido em um frasco e posteriormente filtrado em membrana de nitrato de celulose para quantificação como descrito abaixo para a fração fina. Alíquotas de 0,3 a $1 \mathrm{~L}$ da amostra já peneirada foram então submetidas a uma filtragem com filtros de nitrato de celulose com porosidade nominal de 0,45 $\mu \mathrm{m}$, nos quais foi retida a fração de sedimentos finos em suspensão. Para a quantificação, os filtros de nitrato de celulose foram secos em estufa à $60^{\circ} \mathrm{C}$ até peso constante ( 72 horas). Os filtros foram então resfriados em dessecador e pesados e, após a coleta dos sedimentos grossos e finos sobre os mesmos por filtração, foram novamente submetidos a este processo. A diferença entre o peso inicial e o final corresponde à concentração de sedimentos (FISP, 2000).

\subsection{Análises Estatísticas}

Para auxiliar na interpretação e discussão dos resultados obtidos foram empregados testes estatísticos não paramétricos, por serem considerados testes mais robustos, levando-se em conta que as variáveis estudadas não apresentaram distribuição normal e os pontos analisados eram dependentes entre si (Zar, 1984).

O primeiro teste utilizado consistiu de uma Análise de Variância (ANOVA), na qual procurou-se identificar diferenças estatísticas significativas entre as médias das concentrações de íons e parâmetros físico-químicos dos pontos estudados, permitindo assim avaliar características da variabilidade espacial nas águas desta bacia hidrográfica. 
Para avaliar as variações sazonais nos pontos para os quais dispúnhamos de dados de descarga, o teste utilizado foi a correlação de Spearman (Motulsky, 1995), enquanto que, para os pontos desprovidos deste parâmetro, utilizou-se Mann-Whitney, também conhecido como teste-U.

Todos os testes fazem parte do pacote “STATISTICA 5.5”, e os índices de confiança considerado foram: valores de $\mathrm{P}<0,01$ corresponderam às diferenças altamente significativas; $\mathrm{P}<0,05$ às diferenças significativas e; $\mathrm{P}>0,05$ para as variáveis que não apresentaram diferenças estatísticas significativas. 


\section{RESULTADOS E DISCUSSÃO}

\subsection{Comportamento Hidrológico}

Apesar de não dispormos de medidas de descarga para todos os locais amostrados, foi possível descrever o comportamento da hidrógrafa no período em estudo (Figura 5) a partir de dados obtidos junto à ANA, disponíveis para 6 dos nossos 14 pontos de coleta: COM-2, PB-2, JIP-1, JIP-2, JIP-4 e MAC. Com base nestes dados, foi possível distinguir os períodos de cheia e seca e testar a representatividade do período compreendido por este estudo, em relação às variações observadas nos últimos 17 anos. Na Figura 6 observa-se que os valores mensais de descarga do rio Ji-Paraná durante os anos amostrados (1999 a 2002), apresentaram a mesma ordem de grandeza das médias mensais de longo período (1985 a 2001). O mesmo padrão foi observado para os outros rios (Comemoração, Pimenta Bueno e Machadinho) e, portanto, pode-se afirmar que os dados aqui discutidos são representativos de distintas descargas ao longo da hidrógrafa.

\subsection{Características Gerais: Diagramas Ternários}

Para determinar as características gerais da química das águas dos rios da bacia do rio Ji-Paraná foram utilizados diagramas ternários (Figuras 7 e 8), que foram gerados a partir da proporção relativa das concentrações de cada um dos íons maiores $\left(\mathrm{Na}^{+}, \mathrm{K}^{+}\right.$, $\mathrm{Ca}^{2+}, \mathrm{Mg}^{2+}, \mathrm{HCO}_{3}{ }^{-}, \mathrm{CO}_{3}{ }^{2-}, \mathrm{Cl}^{-}$e $\left.\mathrm{SO}_{4}{ }^{2-}\right)$.

Estes diagramas são úteis para: (a) demonstrar os "tipos" de águas de maneira 


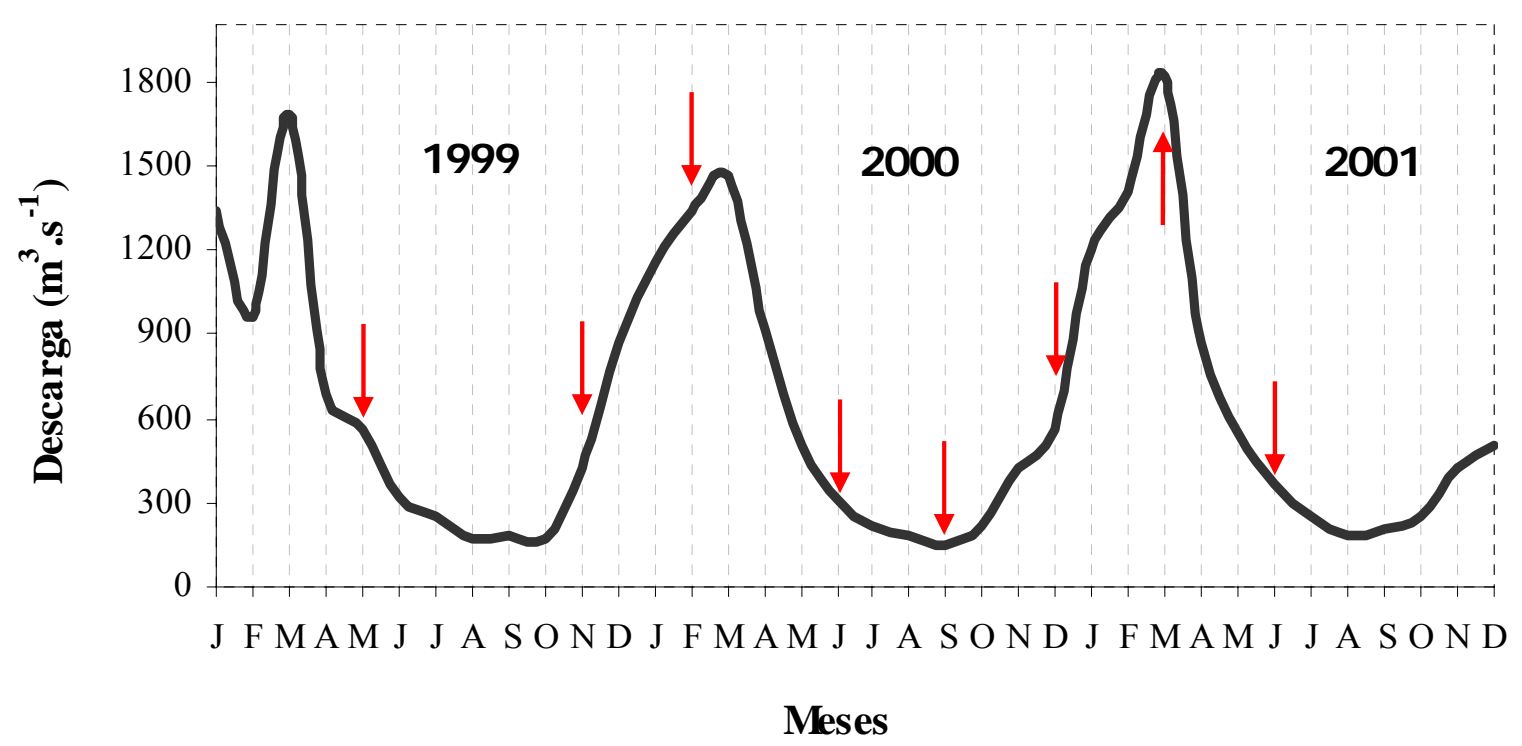

Figura 5 - Descargas diárias, $\mathrm{em} \mathrm{m}^{3} \cdot \mathrm{s}^{-1}$, do rio Ji-Paraná, na cidade de Ji-Paraná, durante o período de 1999 a 2001. As setas indicam os meses em que foram efetuadas as coletas de amostras

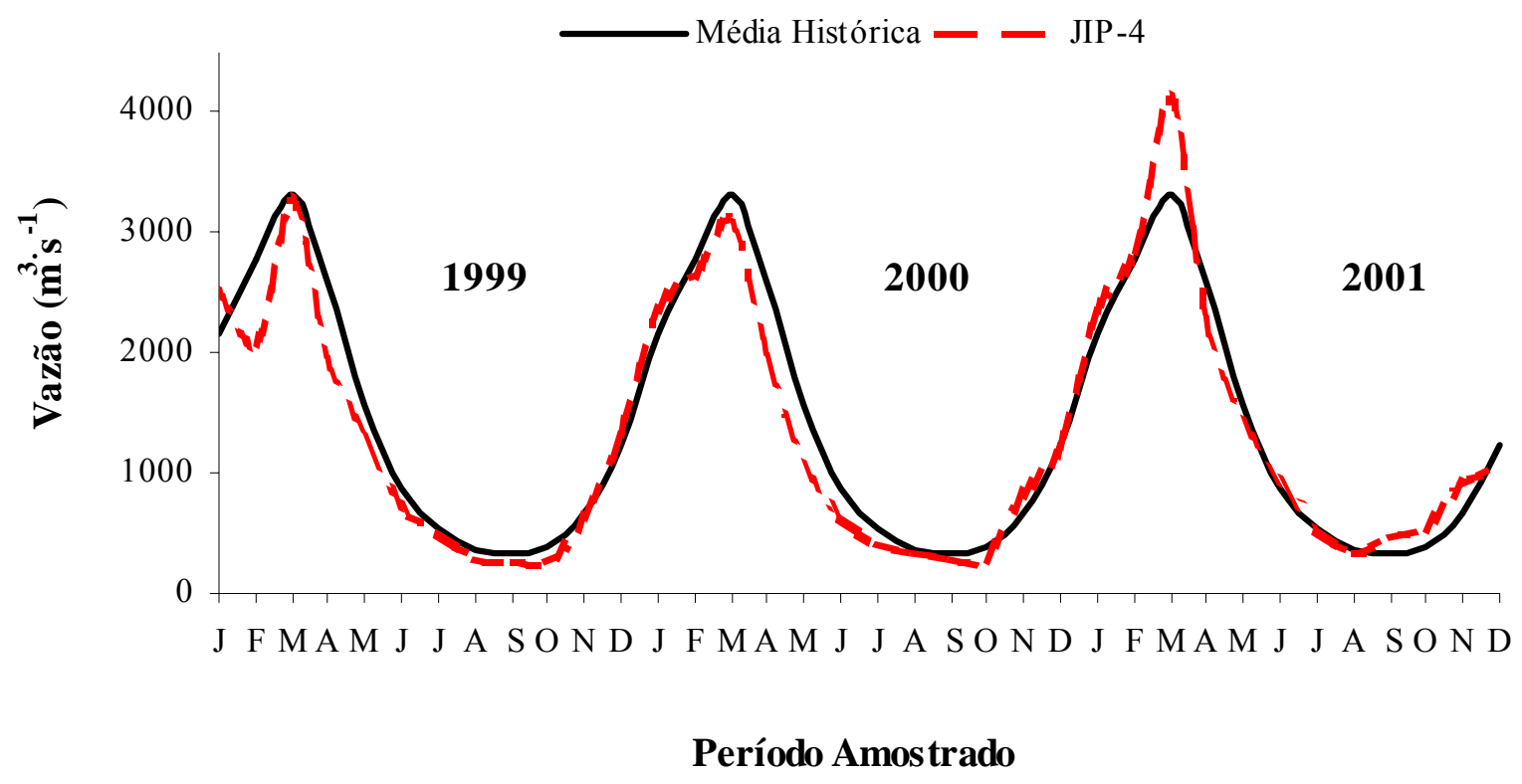

Figura 6 - Descargas diárias no rio Ji-Paraná, $\mathrm{em} \mathrm{m}^{3} \cdot \mathrm{s}^{-1}$ no ponto próximo da cidade de Tabajara (JIP-4). A curva contínua (preta) corresponde à média histórica (1985-2001) e a descontínua (vermelha) à vazão no período de estudo 


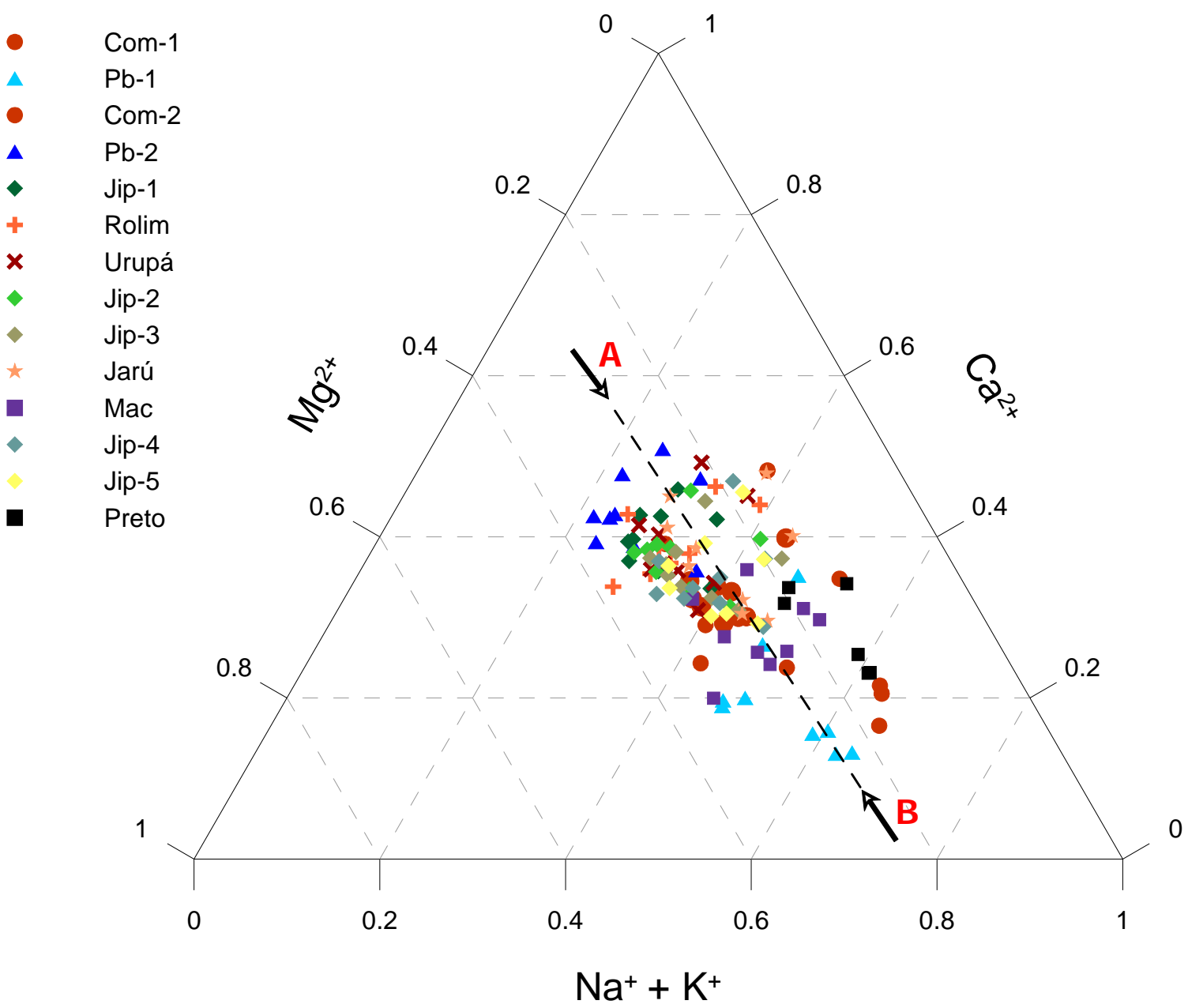

Figura 7 - Diagrama ternário elaborado a partir das concentrações dos cátions maiores nas amostras de água dos rios da bacia do Ji-Paraná, onde A corresponde aos pontos que apresentaram predominância de $\mathrm{Ca}^{2+}$ e $\mathrm{B}$, predominância de $\mathrm{Na}^{+}$ $+\mathrm{K}^{+}$ 


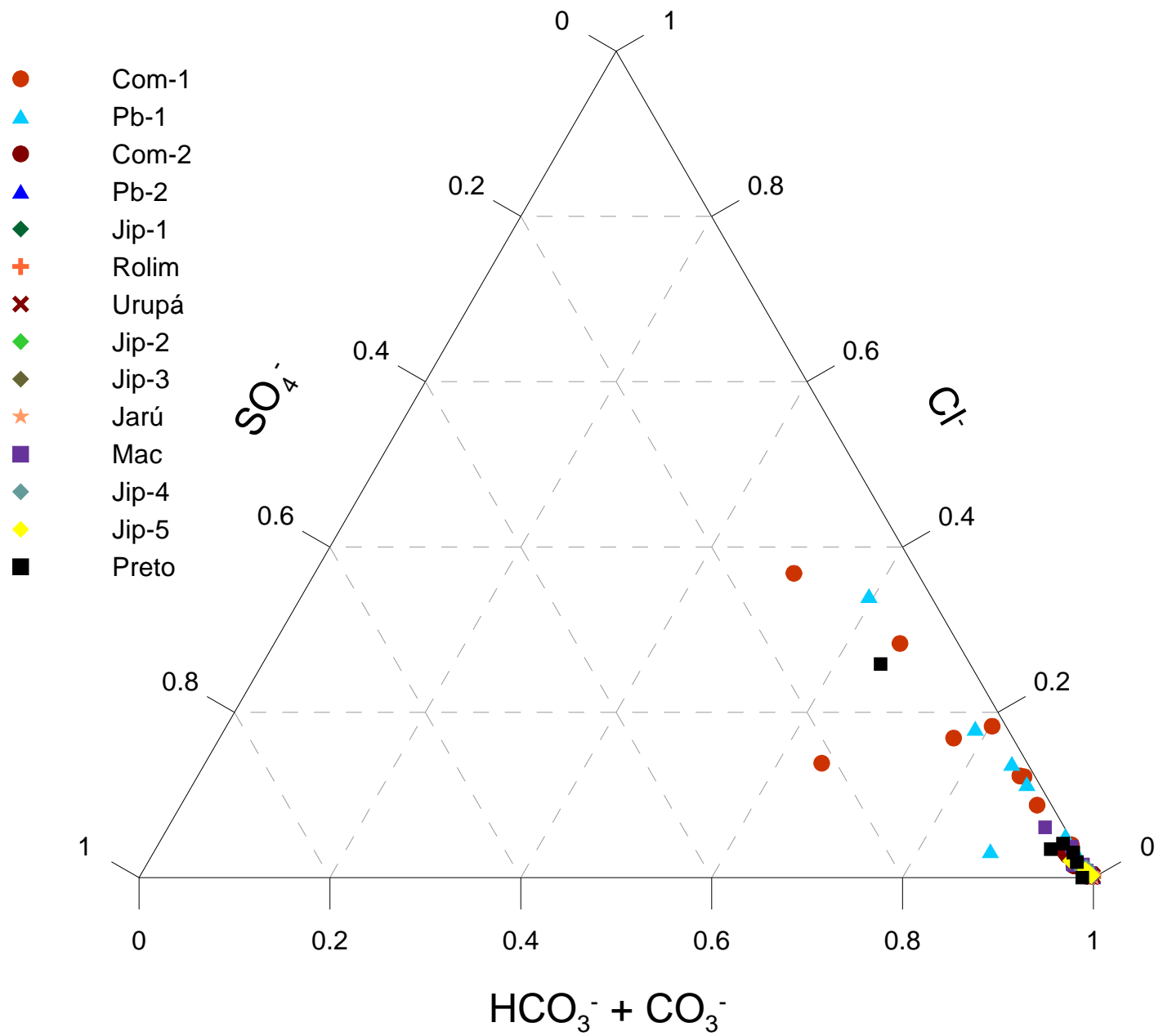

Figura 8 - Diagrama ternário elaborado a partir das concentrações dos ânions maiores nas amostras de água dos rios da bacia do Ji-Paraná 
visualmente clara, e; (b) testar se a composição química das mesmas resulta da mistura de fontes distintas (Drever, 1997).

Os cátions apresentaram uma dispersão ao longo do eixo unindo a região de predominância de $\mathrm{Na}^{+}+\mathrm{K}^{+}$com a de $\mathrm{Ca}^{2+}$, com as cabeceiras dos rios Comemoração e Pimenta Bueno concentrando-se no primeiro grupo, das águas sódicas, e rios como o Urupá e o trecho mais a jusante do Pimenta Bueno no segundo grupo, das cálcicas. O restante dos pontos dispersou-se ao longo deste eixo, na porção central do diagrama ternário, não apresentando, portanto, predominância evidente de nenhum destes grupos (Figura 7). Segundo Drever (1997), este tipo de dispersão ao longo de uma reta é indicativo de águas cuja composição química resulta da mistura de duas fontes predominantes e com origens distintas.

Neste caso, esta composição pode ser explicada pela mistura de águas mais ricas em sódio e potássio, presente nas nascentes dos principais formadores do Ji-Paraná (rios Pimenta Bueno e Comemoração), com águas onde predomina cálcio, provenientes dos rios Pimenta Bueno, Rolim de Moura, Urupá e Jarú.

Em relação aos ânions, observa-se através da Figura 8 que a maioria dos pontos amostrados apresentou predomínio de bicarbonato, excetuando-se as cabeceiras dos rios Comemoração (COM-1) e Pimenta Bueno (PB-1), além do rio Preto, que apresentaram influência relativa de cloreto.

$\mathrm{Na}$ Tabela 2 são apresentados detalhes sobre os locais de amostragem e frequência das coletas, bem como os valores médios dos principais parâmetros físicoquímicos (condutividade elétrica, $\mathrm{pH}$ e temperatura), e das concentrações de sedimentos totais em suspensão. Os valores médios dos principais elementos dissolvidos $\left(\mathrm{Na}^{+}, \mathrm{Ca}^{2+}\right.$, $\mathrm{Mg}^{2+}, \mathrm{K}^{+}, \mathrm{HCO}_{3}^{-}, \mathrm{CO}_{3}^{-}, \mathrm{Cl}^{-}, \mathrm{SO}_{4}{ }^{2-}, \mathrm{NO}_{3}^{-}, \mathrm{NO}_{2}^{-}, \mathrm{NH}_{4}{ }^{+}$e $\mathrm{PO}_{4}{ }^{3-}$ ) analisados nas águas do rio Ji-Paraná e seus principais tributários, são apresentados na Tabela 3 e discutidos a seguir. 


\subsection{Variações Espaciais}

Os íons dissolvidos apresentaram uma ampla variabilidade espacial, com exceção do elemento $\mathrm{SO}_{4}{ }^{2-}$, que não apresentou diferenças estatísticas significativas entre os pontos amostrados $(\mathrm{p}>0,05)$. A partir da Figura 9, observa-se que os menores valores médios de condutividade elétrica foram encontrados nas nascentes dos rios Pimenta Bueno $\left(8,1 \mu \mathrm{S} . \mathrm{cm}^{-1}\right)$ e Comemoração $\left(8,6 \mu \mathrm{S} . \mathrm{cm}^{-1}\right)$, enquanto os maiores foram encontrados nos tributários Rolim de Moura $\left(63,0 . \mu \mathrm{S} . \mathrm{cm}^{-1}\right)$, Urupá $\left(60,0 . \mu \mathrm{S} . \mathrm{cm}^{-1}\right) \mathrm{e}$ Jarú $\left(51,0 . \mu \mathrm{S} . \mathrm{cm}^{-1}\right)$. Nos 5 pontos amostrados no rio Ji-Paraná os valores encontrados foram intermediários a estes (cerca de $30,0 \mu \mathrm{S} . \mathrm{cm}^{-1}$ ). Nos trechos localizados mais à jusante no canal principal do rio Ji-Paraná foi observada uma considerável diluição nas concentrações dos íons dissolvidos, resultante provavelmente do aporte do afluente Machadinho (mais pobre em íons) e de outros rios, regionalmente denominados de igarapés, não quantificados neste estudo.

A condutividade elétrica de uma amostra de água natural é determinada, via de regra, pelas concentrações dos chamados íons maiores, sódio, cálcio, magnésio, potássio, carbonatos, cloreto e sulfato. Portanto, como seria esperado e, a exceção do sulfato, as variações espaciais destes íons são muito similares àquelas observadas para a condutividade elétrica (Figuras 10 e 11). Tal variabilidade apresenta estreita relação com as características químicas dos solos da bacia, uma vez que a região central da bacia, onde foram encontradas as maiores concentrações de íons dissolvidos, apresenta também, os solos mais férteis da mesma ${ }^{1}$ (Ballester et al., 2003).

Analisando-se o pH, observou-se que as cabeceiras dos rios Comemoração e Pimenta Bueno apresentaram as águas mais ácidas da bacia, com valores médios de 5,0 e 6,2 respectivamente. À medida que o canal do rio percorre um substrato litológico mais enriquecido (Ballester et al., 2003; Krusche et al., no prelo), os valores vão se tornando neutros (Figura 12), em função do aumento da capacidade de tamponamento

\footnotetext{
${ }^{1}$ Representada pela presença de maiores teores de cátions em seus solos.
} 
Tabela 2. Locais amostrados, número de coletas (n) e valores médios de $\mathrm{pH}$, condutividade elétrica (Cond.), temperatura (Temp.) e sedimentos totais em suspensão (STS) nos pontos amostrados na bacia do rio Ji-Paraná

\begin{tabular}{cccccccc}
\hline Ponto & Rio & Município & n & Cond. $(\boldsymbol{\mu}$ S.cm-1) & pH & Temp ( $\left.{ }^{\circ} \mathbf{C}\right)$ & STS (mg/L) \\
\hline Canal Principal & & & & & & & \\
JIP-1 & Ji-Paraná & Cacoal & 9 & $27.0 \pm 3.2$ & $6.6 \pm 0.4$ & $27.2 \pm 1.3$ & $31.9 \pm 20.8$ \\
JIP-2 & Ji-Paraná & Ji-Paraná & 9 & $35.8 \pm 4.5$ & $6.5 \pm 0.6$ & $27.9 \pm 1.6$ & $34.1 \pm 25.4$ \\
JIP-3 & Ji-Paraná & Jarú & 9 & $36.1 \pm 2.5$ & $6.8 \pm 0.4$ & $28.5 \pm 1.4$ & $31.5 \pm 20.0$ \\
JIP-4 & Ji-Paraná & Tabajara & 9 & $29.4 \pm 6.6$ & $6.4 \pm 0.6$ & $28.2 \pm 1.1$ & $25.4 \pm 18.1$ \\
JIP-5 & Ji-Paraná & Calama & 8 & $28.8 \pm 6.5$ & $6.4 \pm 0.6$ & $29.2 \pm 1.5$ & $25.4 \pm 16.4$ \\
Tributários & & & & & & \\
COM-1 & Comemoração & Vilhena & 9 & $8.6 \pm 3.2$ & $5.1 \pm 0.4$ & $24.1 \pm 1.3$ & $7.4 \pm 5.3$ \\
COM-2 & Comemoração & Pimenta Bueno & 9 & $13.2 \pm 3.5$ & $6.2 \pm 0.3$ & $26.6 \pm 0.9$ & $28.3 \pm 22.2$ \\
PB-1 & Pimenta Bueno & Vilhena & 9 & $8.1 \pm 2.9$ & $5.4 \pm 0.6$ & $24.3 \pm 1.3$ & $19.3 \pm 9.8$ \\
PB-2 & Pimenta Bueno & Pimenta Bueno & 9 & $34.8 \pm 5.1$ & $6.6 \pm 0.4$ & $26.9 \pm 1.2$ & $38.7 \pm 25.2$ \\
ROLIM & Rolim de Moura & Cacoal & 8 & $62.6 \pm 8.7$ & $6.7 \pm 0.5$ & $27.0 \pm 2.0$ & $37.0 \pm 13.5$ \\
URUPÁ & Urupá & Ji-Paraná & 9 & $60.1 \pm 14.2$ & $6.8 \pm 0.5$ & $28.2 \pm 1.4$ & $22.6 \pm 17.5$ \\
JARÚ & Jarú & Jarú & 9 & $50.7 \pm 8.3$ & $6.7 \pm 0.4$ & $27.8 \pm 1.5$ & $25.8 \pm 16.7$ \\
MAC & Machadinho & Machadinho d'Oeste & 9 & $21.9 \pm 12.4$ & $6.0 \pm 0.4$ & $26.7 \pm 1.7$ & $17.9 \pm 9.1$ \\
PRETO & Preto & Calama & 6 & $8.9 \pm 3.1$ & $5.4 \pm 0.4$ & $28.3 \pm 1.5$ & $7.7 \pm 2.0$ \\
\hline
\end{tabular}

deste sistema. Isto pode ser explicado pelos altos valores de Capacidade Efetiva de Troca de Cátions (CETC) dos solos, principalmente na porção central da bacia (rio JiParaná e tributários Rolim de Moura, Urupá e Jarú) que se refletem, também, no aumento das concentrações de carbonatos (Figura 11). Nos dois últimos tributários, Machadinho e Preto, drenando solos com características semelhantes àquelas observas nos formadores do rio Ji-Paraná (Comemoração e Pimenta Bueno), o pH volta a apresentar-se mais ácido em relação aos pontos localizados no canal principal, com médias de 5,9 e 5,5 respectivamente (Figura 12).

As maiores concentrações de sedimentos totais em suspensão foram encontradas nos tributários Comemoração e Pimenta Bueno, próximos de sua confluência, e no rio Rolim de Moura, com 19,34, 38,67 e 37,03 mg.L ${ }^{-1}$, respectivamente (Figura 13).

Não foram encontradas diferenças estatisticamente significativas $(p<0,01)$ entre os cinco pontos amostrados no canal principal do rio Ji-Paraná, que apresentaram uma 
Tabela 3. Composição química dos principais elementos dissolvidos (íons maiores e nutrientes) do rio Ji-Paraná e seus principais tributários (Valores expressos em $\mu \mathrm{M}$ )

\begin{tabular}{|c|c|c|c|c|c|c|c|c|c|c|c|c|c|}
\hline Ponto & $\mathbf{T Z}^{+}$ & $\mathbf{T Z}$ & $\mathrm{Na}^{+}$ & $\mathrm{Ca}^{2+}$ & $\mathbf{M g}^{2+}$ & $\mathbf{K}^{+}$ & $\mathrm{HCO}_{3}{ }^{-}$ & $\mathrm{Cl}^{-}$ & $\mathrm{SO}_{4}{ }^{2-}$ & $\mathrm{NO}_{3}{ }^{-}$ & $\mathrm{NO}_{2}^{-}$ & $\mathbf{N H}_{4}{ }^{+}$ & $\mathbf{P O}_{4}{ }^{3-}$ \\
\hline \multicolumn{14}{|c|}{ Canal Principal } \\
\hline JIP - 1 & $277,0 \pm 27,8$ & $222,7 \pm 43,4$ & $43,0 \pm 6,1$ & $55,2 \pm 7,6$ & $41,5 \pm 8,7$ & $40,7 \pm 9,3$ & $123,0 \pm 34,3$ & $11,2 \pm 2,9$ & $2,6 \pm 1,1$ & $9,4 \pm 2,2$ & $7,9 \pm 10,3$ & $4,5 \pm 2,6$ & $0,7 \pm 0,7$ \\
\hline JIP - 2 & $368,1 \pm 4,5$ & $316,5 \pm 47,9$ & $70,3 \pm 14,1$ & $69,3 \pm 6,7$ & $53,1 \pm 11,7$ & $53,2 \pm 12,6$ & $158,3 \pm 65,9$ & $23,9 \pm 12,74$ & $2,7 \pm 1,0$ & $12,2 \pm 8,5$ & $6,3 \pm 4,3$ & $3,8 \pm 0,9$ & $0,5 \pm 0,7$ \\
\hline JIP - 3 & $371,3 \pm 2,5$ & $370,9 \pm 122,9$ & $72,9 \pm 13,3$ & $67,1 \pm 7,2$ & $51,7 \pm 11,8$ & $60,9 \pm 19,3$ & $235,9 \pm 67,0$ & $17,2 \pm 10,0$ & $2,9 \pm 1,3$ & $9,3 \pm 4,1$ & $6,8 \pm 4,2$ & $4,5 \pm 2,0$ & $0,8 \pm 0,6$ \\
\hline JIP - 4 & $302,7 \pm 6,6$ & $254,0 \pm 19,0$ & $61,5 \pm 16,5$ & $52,6 \pm 7,2$ & $41,3 \pm 12,1$ & $53,6 \pm 13,8$ & $122,6 \pm 62,4$ & $17,1 \pm 7,9$ & $2,9 \pm 2,1$ & $7,3 \pm 5,6$ & $5,5 \pm 4,1$ & $4,0 \pm 1,7$ & $0,7 \pm 0,6$ \\
\hline JIP - 5 & $289,5 \pm 6,5$ & $256,2 \pm 60,9$ & $59,4 \pm 13,0$ & $50,9 \pm 9,8$ & $37,9 \pm 10,7$ & $52,5 \pm 17,2$ & $101,8 \pm 68,6$ & $14,8 \pm 5,5$ & $2,9 \pm 1,5$ & $5,8 \pm 4,1$ & $5,3 \pm 4,4$ & $3,6 \pm 0,8$ & $0,3 \pm 0,4$ \\
\hline \multicolumn{14}{|l|}{ Tributários } \\
\hline COM-1 & $25,4 \pm 10,0$ & $48,3 \pm 15,3$ & $7,4 \pm 3,4$ & $3,8 \pm 2,4$ & $2,8 \pm 1,9$ & $4,7 \pm 3,7$ & $2,2 \pm 1,7$ & $7,7 \pm 4,7$ & $1,4 \pm 1,9$ & $9,4 \pm 1,6$ & $1,1 \pm 0,5$ & $3,7 \pm 1,5$ & $0,4 \pm 0,4$ \\
\hline COM - 2 & $113,1 \pm 23,8$ & $96,1 \pm 31,0$ & $20,6 \pm 4,7$ & $18,5 \pm 4,3$ & $15,0 \pm 4,3$ & $25,3 \pm 6,5$ & $30,6 \pm 14,2$ & $11,1 \pm 6,4$ & $2,8 \pm 0,7$ & $8,4 \pm 1,8$ & $2,4 \pm 1,0$ & $4,2 \pm 1,8$ & $0,6 \pm 0,9$ \\
\hline PB - 1 & $42,5 \pm 6,5$ & $46,4 \pm 16,4$ & $6,0 \pm 2,4$ & $4,3 \pm 1,9$ & $5,6 \pm 1,7$ & $16,7 \pm 2,0$ & $5,7 \pm 7,3$ & $5,7 \pm 1,5$ & $1,2 \pm 2,3$ & $12,3 \pm 1,8$ & $1,3 \pm 0,4$ & $3,6 \pm 1,3$ & $0,1 \pm 0,2$ \\
\hline PB - 2 & $357,6 \pm 42,5$ & $281,1 \pm 93,2$ & $47,9 \pm 7,9$ & $77,2 \pm 13,4$ & $55,6 \pm 13,6$ & $44,3 \pm 12,6$ & $154,9 \pm 64,7$ & $10,4 \pm 2,6$ & $2,8 \pm 1,4$ & $10,7 \pm 2,9$ & $6,6 \pm 4,1$ & $3,9 \pm 1,4$ & $0,8 \pm 0,8$ \\
\hline ROLIM & $653,0 \pm 95,9$ & $609,3 \pm 80,8$ & $139,8 \pm 27,5$ & $128,4 \pm 22,0$ & $94,2 \pm 27,3$ & $68,0 \pm 26,7$ & $296,2 \pm 154,8$ & $20,5 \pm 17,0$ & $2,4 \pm 1,6$ & $4,3 \pm 2,1$ & $11,1 \pm 6,9$ & $3,8 \pm 0,7$ & $1,3 \pm 0,8$ \\
\hline URUPA & $633,2 \pm 14,2$ & $566,2 \pm 145,7$ & $122,6 \pm 29,6$ & $121,7 \pm 23,8$ & $88,1 \pm 25,7$ & $91,1 \pm 56,8$ & $385,8 \pm 184,8$ & $23,7 \pm 16,0$ & $4,6 \pm 4,4$ & $6,7 \pm 2,5$ & $13,1 \pm 9,6$ & $2,5 \pm 0,8$ & $0,8 \pm 0,7$ \\
\hline JARU & $553,1 \pm 8,3$ & $520,1 \pm 153,4$ & $108,7 \pm 14,2$ & $104,5 \pm 22,5$ & $66,0 \pm 20,3$ & $103,4 \pm 52,9$ & $323,4 \pm 87,8$ & $26,7 \pm 16,5$ & $4,2 \pm 3,2$ & $6,2 \pm 1,4$ & $10,0 \pm 6,6$ & $4,8 \pm 2,8$ & $0,8 \pm 1,0$ \\
\hline MAC & $166,0 \pm 12,4$ & $158,8 \pm 20,1$ & $35,3 \pm 7,9$ & $23,3 \pm 5,8$ & $21,2 \pm 6,4$ & $41,6 \pm 11,1$ & $47,4 \pm 32,8$ & $13,0 \pm 5,3$ & $2,4 \pm 1,8$ & $9,0 \pm 6,5$ & $4,7 \pm 2,0$ & $4,3 \pm 1,6$ & $0,4 \pm 0,7$ \\
\hline PRETO & $52,7 \pm 3,1$ & $83,0 \pm 22,3$ & $15,72 \pm 7,7$ & $7,6 \pm 3,5$ & $4,2 \pm 1,3$ & $13,3 \pm 5,1$ & $9,3 \pm 4,6$ & $8,8 \pm 2,3$ & $1,7 \pm 0,8$ & $4,1 \pm 2,3$ & $2,3 \pm 0,4$ & $3,4 \pm 2,1$ & $0,1 \pm 0,0$ \\
\hline
\end{tabular}




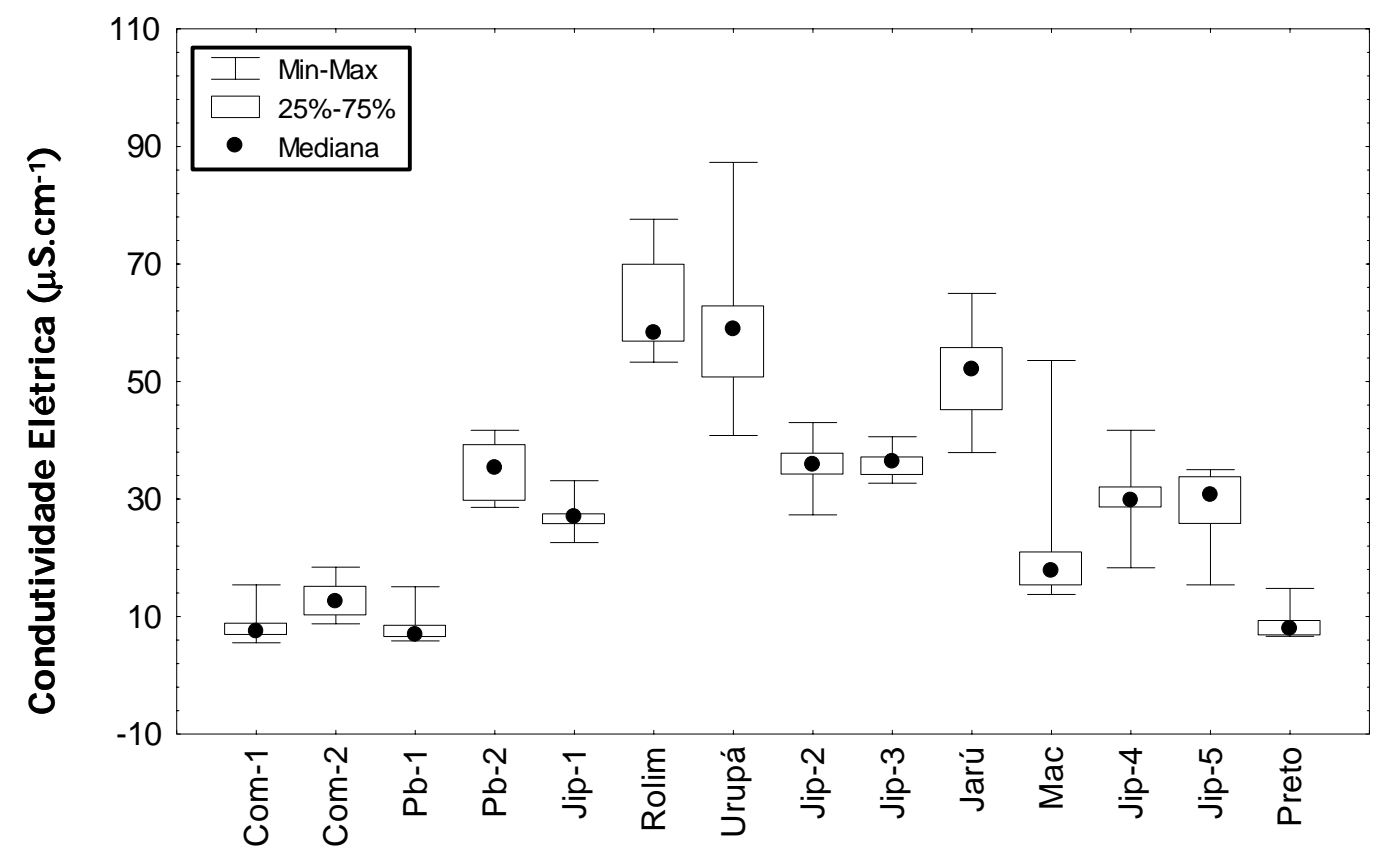

Figura 9 - Condutividade Elétrica média nas águas dos pontos amostrados (valores em $\mu \mathrm{S} . \mathrm{cm}^{-1}$ )

média de aproximadamente $30 \mathrm{mg} \cdot \mathrm{L}^{-1}$. As menores concentrações foram encontradas nas cabeceiras dos rios Comemoração e Machadinho com, respectivamente, 7,4 e 7,7 $\mathrm{mg} . \mathrm{L}^{-1}$, ambos rios com características de águas pretas, que apresentam como principal característica, o fato de serem ricos em matéria orgânica, entretanto, muito pobres em íons inorgânicos dissolvidos e sólidos em suspensão, favorecendo $\mathrm{pH}$ muito ácido em suas águas (Sioli, 1984). Esta distribuição pode ser reflexo do uso e ocupação dos solos da bacia, uma vez que a implantação de pastagem favorece processos erosivos, decorrentes da compactação dos solos (Elsenbeer et al., 1999). Assim, é possível que as sub-bacias que apresentam maiores concentrações de sedimentos em suas águas estejam refletindo o impacto das alterações antropogênicas na dinâmica de transporte de material particulado nestes sistemas.

Apesar do carbono orgânico não apresentar diferenças estatisticamente significativas $(\mathrm{P}<0,05)$ entre os pontos amostrados, observou-se que a distribuição 

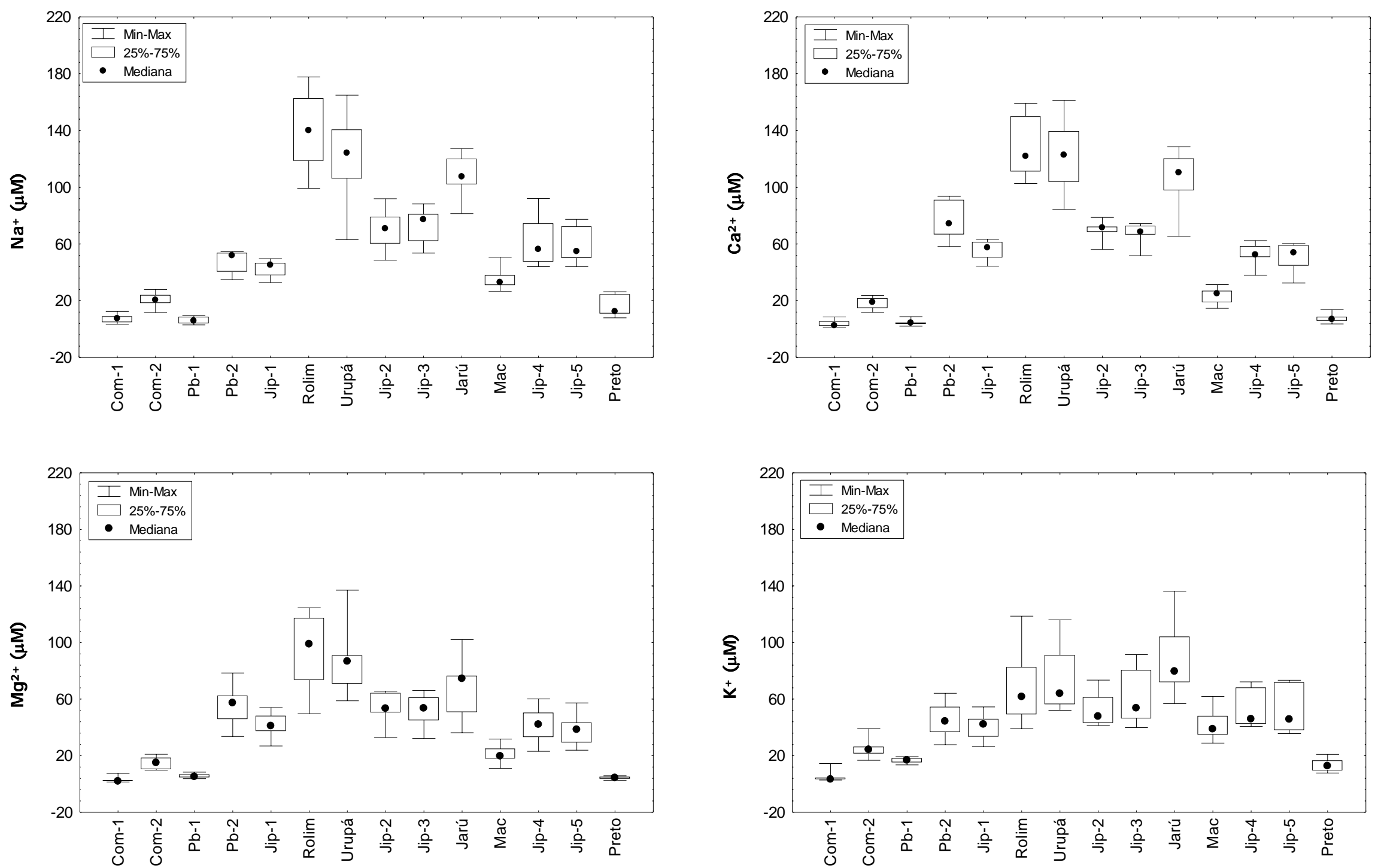

Figura 10 - Concentração média dos cátions maiores nas águas dos rios da bacia do Ji-Paraná (valores em $\mu \mathrm{M}$ ) 

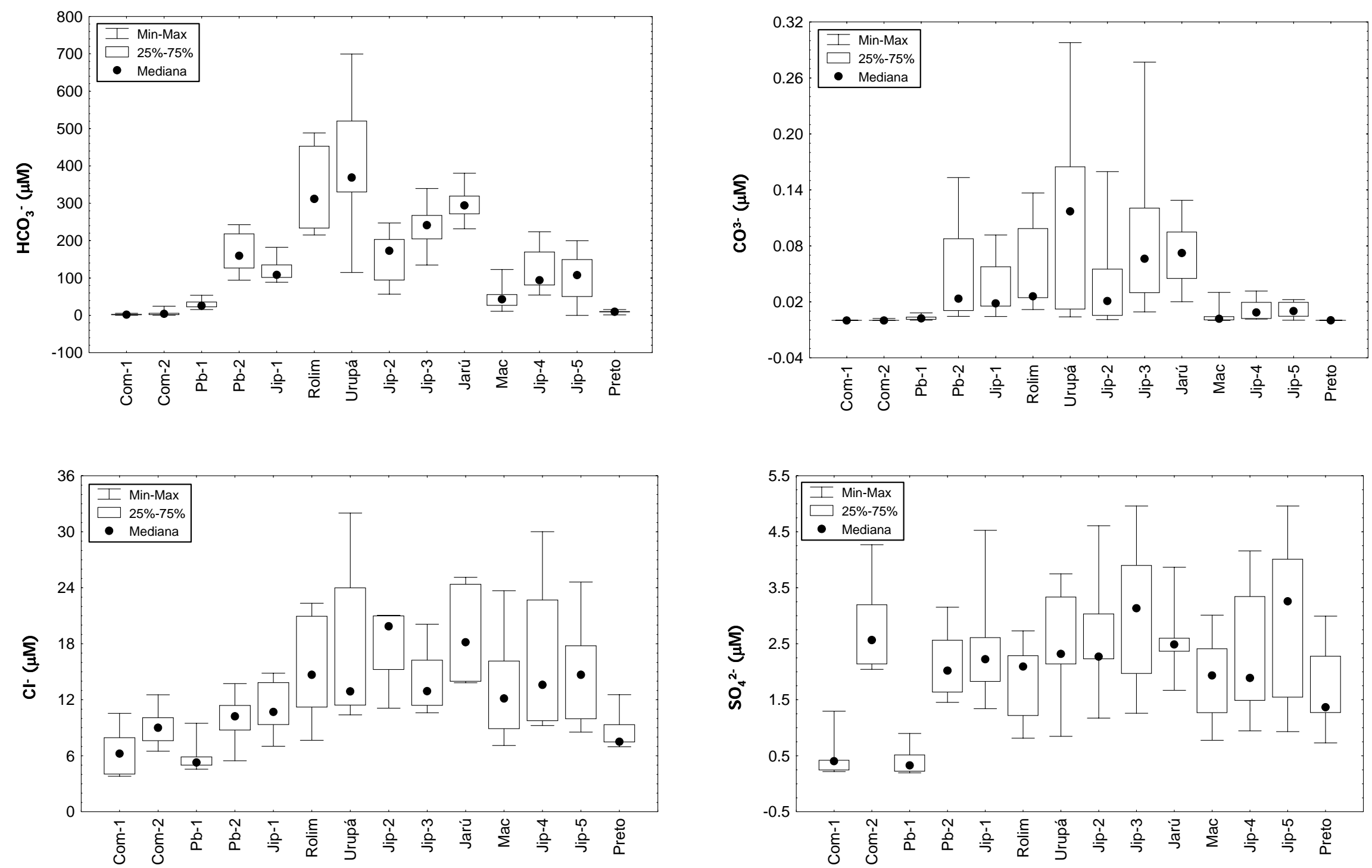

Figura 11 - Concentração média dos ânions maiores nas águas dos rios da bacia do Ji-Paraná (valores em $\mu \mathrm{M}$ ) 


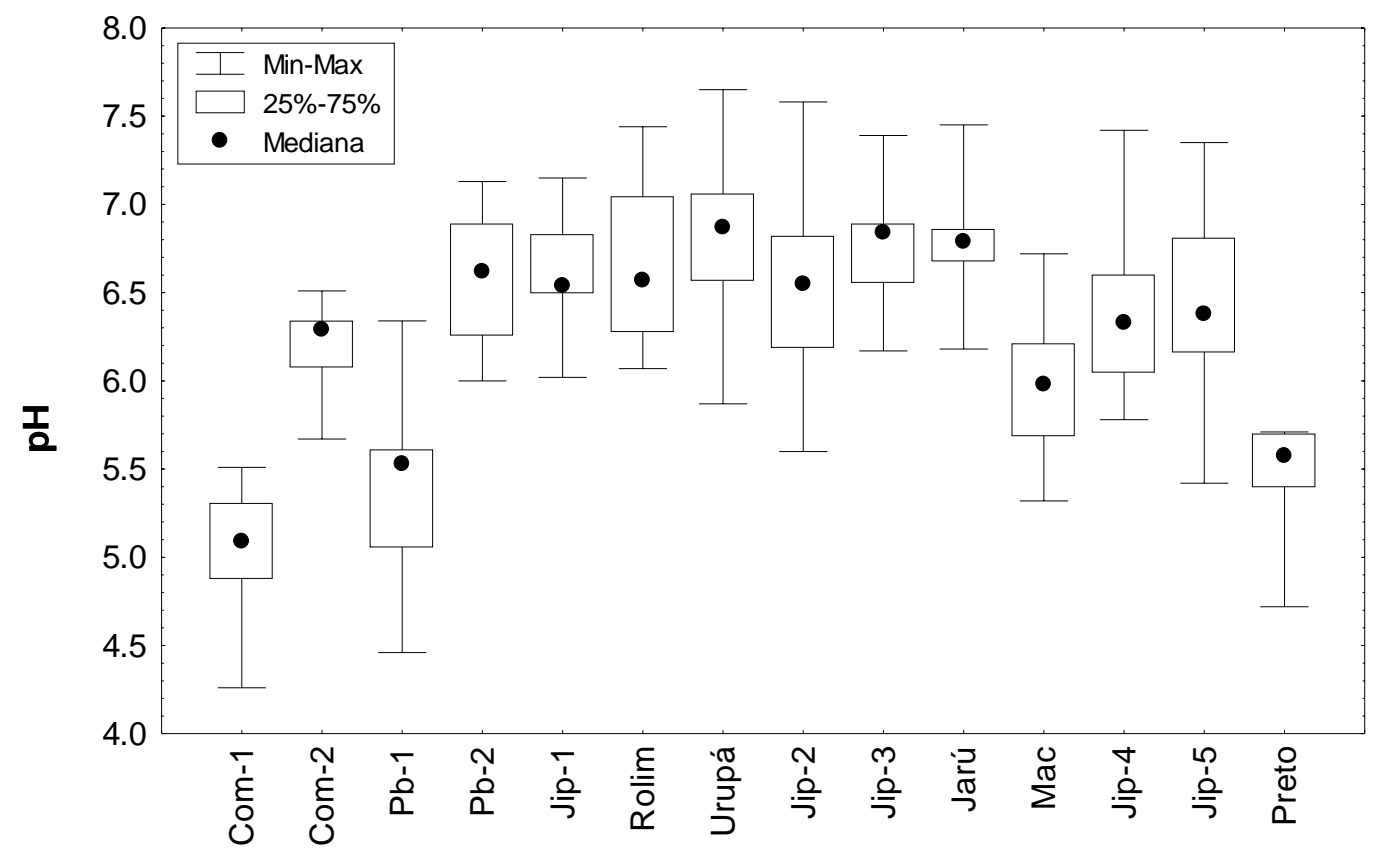

Figura 12 - Valores médios de pH nas águas dos rios da bacia do Ji-Paraná

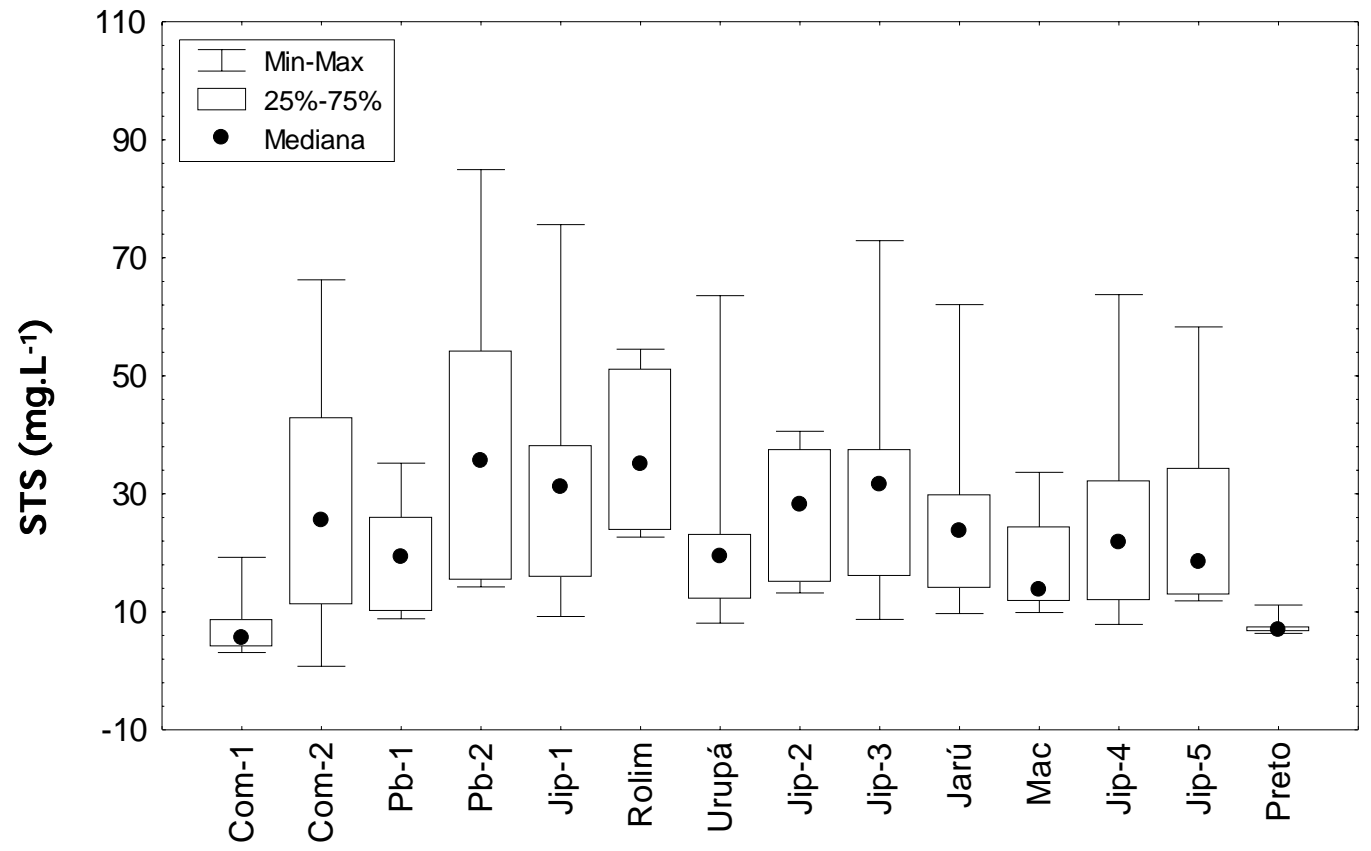

Figura 13 - Concentração de Sedimentos Totais em Suspensão nas águas dos rios da bacia do Ji-Paraná (valores em mg. $\mathrm{L}^{-1}$ ) 
espacial de suas concentrações apresentou padrão similar àquele observado para os íons maiores e sedimentos em suspensão (Figura 14).

Em estudo realizado em uma toposeqüencia na Estação de Manejo Florestal ZF-2 do INPA, ao norte de Manaus, encontrou-se forte correlação entre as concentrações de COD na solução do solo com a textura. Na região localizada sob platô, com solo mais argiloso (latossolo), foram encontradas as menores concentrações, decorrentes da adsorção do COD às partículas de argila. No solo localizado sob baixio, com baixos teores de argila $<15 \%$ (Podzol), foram observados os maiores teores de carbono, disponibilizados em função da baixa capacidade de complexação do solo arenoso (Neu, com. pess.).

Na bacia do Ji-Paraná a variação observada para o carbono orgânico dissolvido foi contrária, e muito distinta do que seria esperado para estes rios. Nas regiões localizadas sob solos mais arenosos, como os rios Comemoração, Pimenta Bueno e Preto, ocorreram as menores concentrações de COD, enquanto os pontos localizados em solos mais argilosos, como os tributários Rolim, Urupá e Jarú, apresentaram as maiores concentrações do mesmo (Figura 14).

Portanto, as maiores concentrações observadas na região central da bacia, podem ser resultantes da existência das pastagens que, ao provocar o aumento da erosão e fluxos subsuperficiais, podem estar propiciando um maior aporte deste nutriente às águas, ou ainda, podem estar sendo magnificadas pelo aporte de esgotos, em função da proximidade destes pontos coletados à cidades. A alta correlação entre COD e Sedimentos Totais em Suspensão $(\mathrm{p}<0,01)$, observada na Figura 15, corrobora esta afirmação.

As formas de nitrogênio inorgânico dissolvido (NID $=\mathrm{NO}_{2}{ }^{-}+\mathrm{NO}_{3}{ }^{-}+\mathrm{NH}_{4}{ }^{+}$) apresentaram grande variação espacial para duas de suas frações, o $\mathrm{NO}_{3}^{-}$e o $\mathrm{NO}_{2}{ }^{-}$. O $\mathrm{NO}_{3}{ }^{-}$correspondeu à fração mais abundante entre os pontos localizados nas regiões menos perturbadas da bacia (Figura 16), sendo possivelmente oriundas do aporte da solução do solo rica neste nutriente e de processos de mineralização da matéria orgânica dentro do canal do rio, conforme observado em outros estudos conduzidos na região 


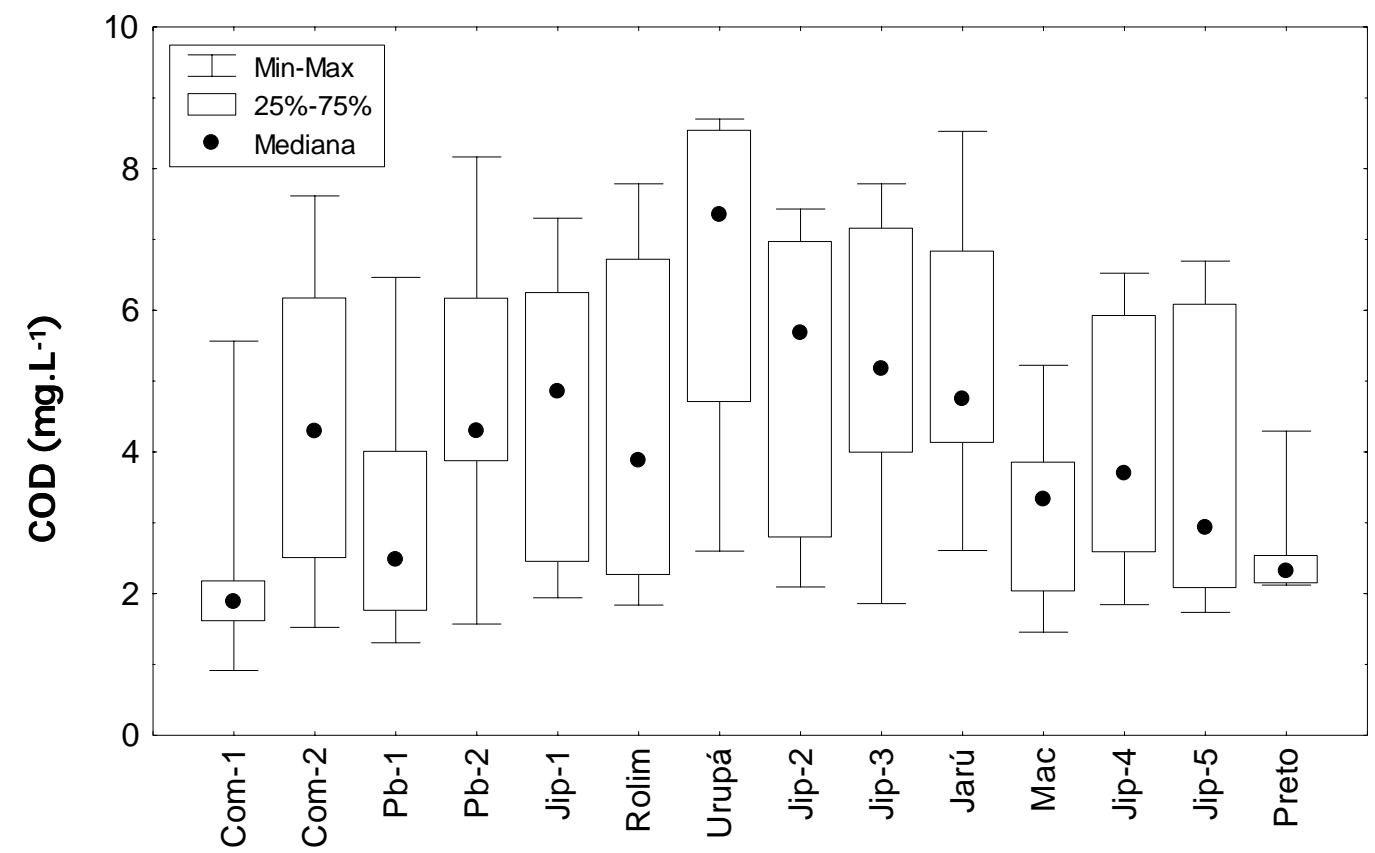

Figura 14 - Concentração de Carbono Orgânico Dissolvido nas águas dos rios da bacia do Ji-Paraná (valores em mg. $\mathrm{L}^{-1}$ )

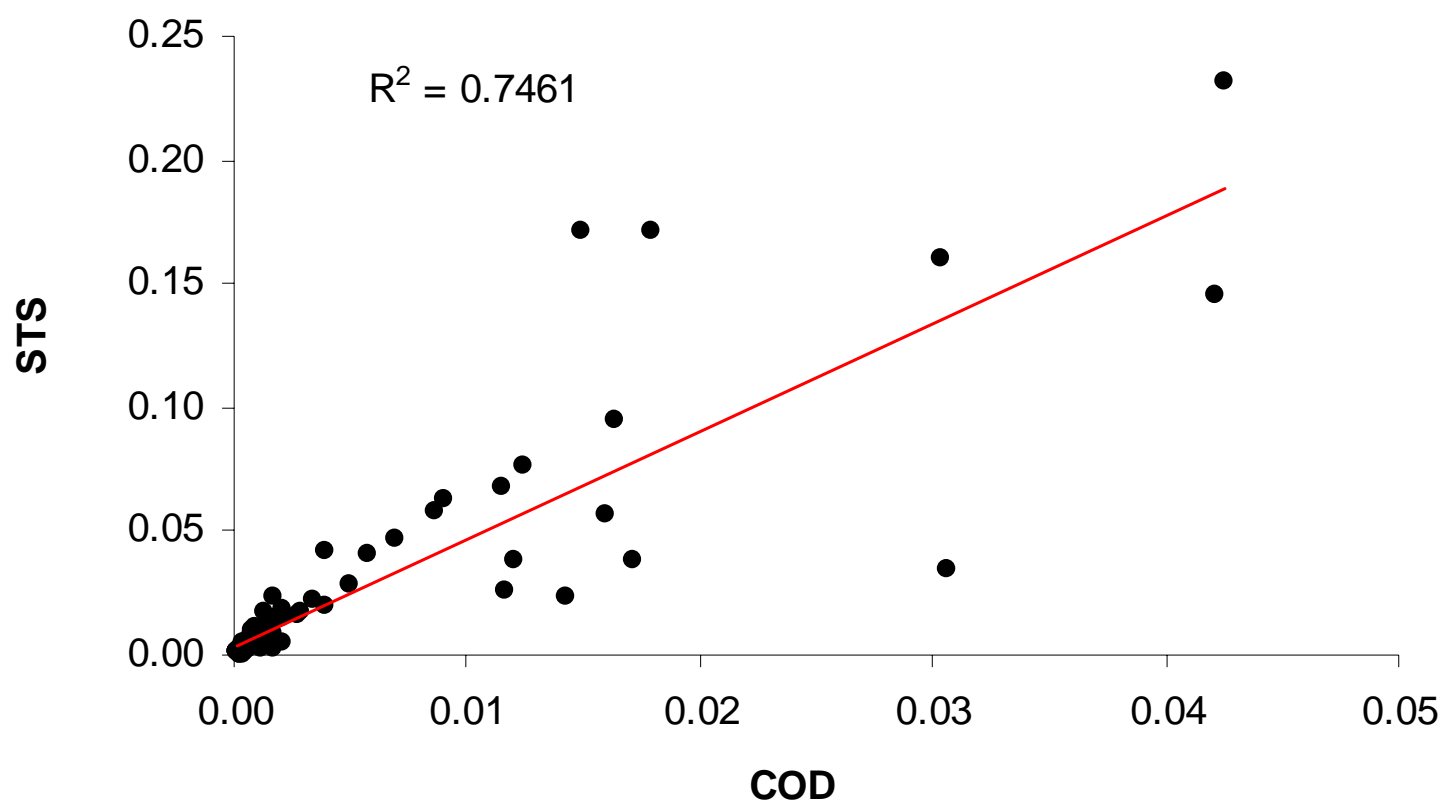

Figura 15 - Relação entre Carbono Orgânico Dissolvido e Sedimentos Totais em Suspensão (as concentrações estão divididas pela área de cada sub-bacia) 
Amazônica (McClain et al., 1994; Neill et al., 2001). Nos rios Rolim de Moura, Urupá e Jarú, o $\mathrm{NO}_{2}{ }^{-}$correspondeu à fração mais importante de NID (Figura 17), sendo provavelmente oriundo de fontes difusas de poluição, em função da proximidade de centros urbanos, e da abundância de pastagens nestas áreas. $\mathrm{O} \mathrm{NH}_{4}^{+}$não apresentou diferença estatisticamente significativa entre os pontos amostrados (Figura 18). Esta característica pode ser atribuída a processos de adsorção ou nitrificação deste composto no solo, reduzindo suas perdas para o sistema fluvial (Jordan, 1987 apud Williams \& Melack, 1997).

$\mathrm{O}$ fósforo solúvel reativo $\left(\mathrm{PO}_{4}{ }^{3-}\right)$ apresentou concentrações muito próximas do limite de detecção do nosso método $(0,52 . \mu \mathrm{M})$ nas cabeceiras do rio Ji-Paraná e nos pontos localizados próximos de onde este desemboca no rio Madeira, ao passo que, na região central da bacia, foram encontradas suas maiores concentrações no ponto Rolim de Moura, com média de 1,28. $\mu \mathrm{M}$ (Figura 19). As baixas concentrações de $\mathrm{PO}_{4}{ }^{3-}$ em relação aos demais solutos se deve ao fato deste composto poder ser fixado por $\mathrm{Fe}$ e $\mathrm{Al}$ ainda no solo, antes de ser lixiviado. Contudo, as maiores concentrações observadas na região central da bacia, possivelmente resultam do arraste deste composto junto com os sedimentos em suspensão, promovidos a partir dos processos erosivos ampliados pela implantação de pastagens nesta região. Este é mais um indicativo que este rio já apresenta sinais das alterações antropogênicas na biogeoquímica de suas águas.

Estes resultados demonstram que, tanto as características gerais, quanto a distribuição espacial dos íons em solução nas águas dos rios da bacia do Ji-Paraná, apresentaram estreita relação com os tipos de solos nas suas respectivas sub-bacias (Figuras 3, 11 e 12).

$\mathrm{Na}$ região das cabeceiras dos rios Comemoração e Pimenta Bueno, os solos são mais arenosos e pobres em cátions (Neossolos Quartzarênicos), ao passo que na região central da bacia encontram-se solos com maiores teores de argila e mais ricos em cátions (Argissolos). Nos setores mais à jusante predominam os latossolos e, com menor freqüência, plintossolos e argissolos.

A ocorrência de afloramentos rochosos nas sub-bacias dos rios Rolim de Moura, 


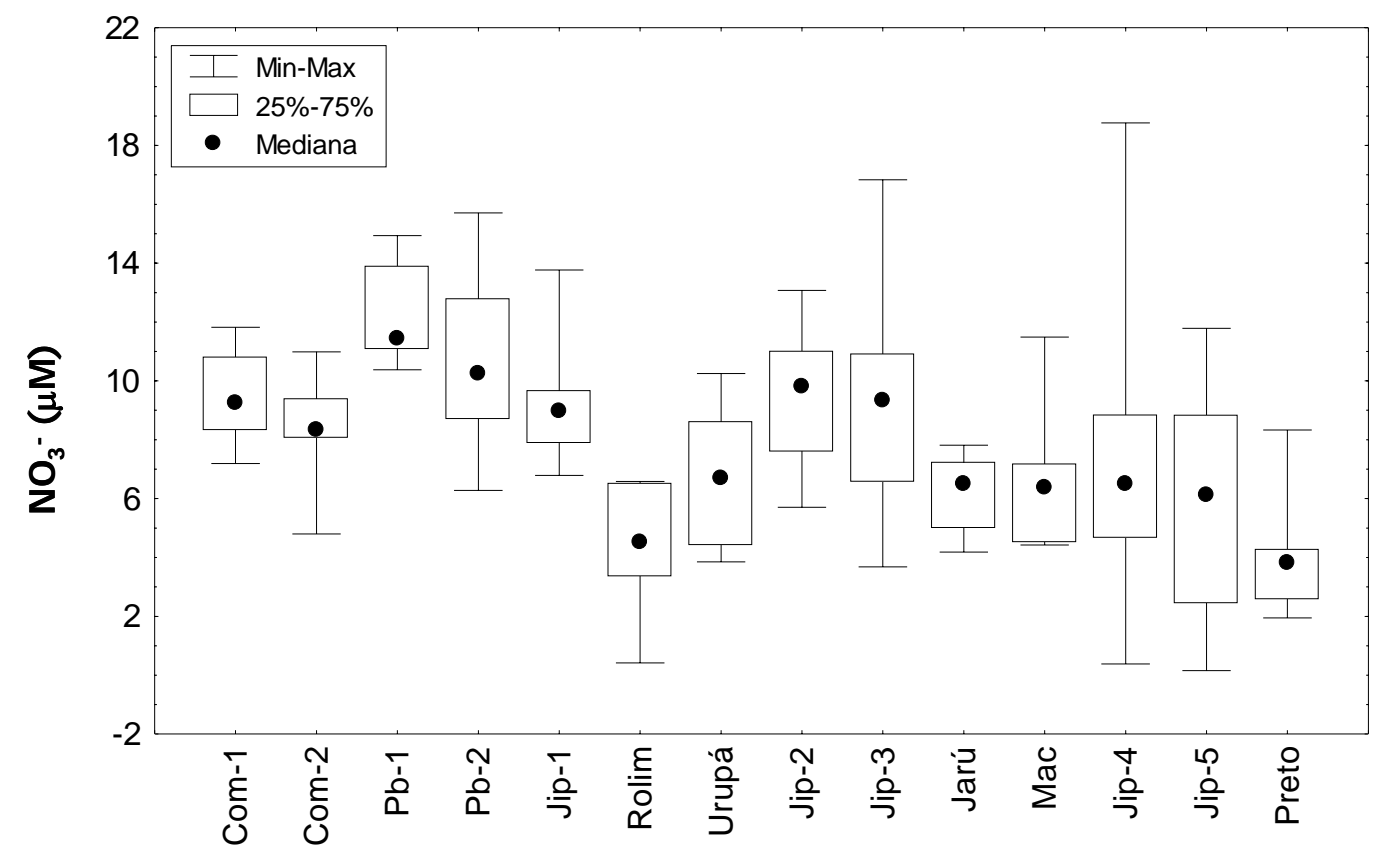

Figura 16 - Variação espacial das concentrações de $\mathrm{NO}_{3}{ }^{-}$nas águas dos rios da bacia do Ji-Paraná (valores em $\mu \mathrm{M}$ )

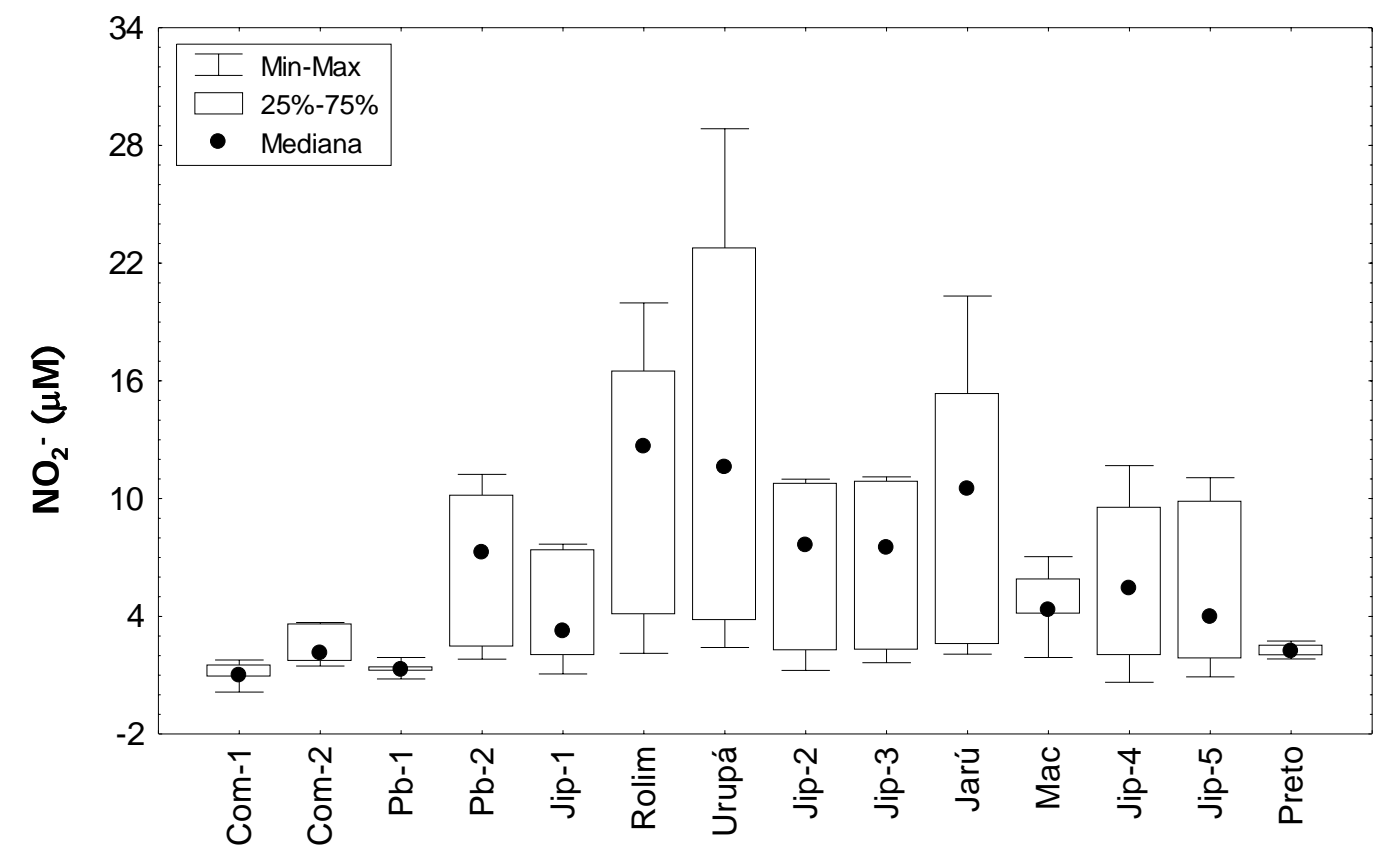

Figura 17 - Variação espacial das concentrações de $\mathrm{NO}_{2}{ }^{-}$nas águas dos rios da bacia do Ji-Paraná (valores em $\mu \mathrm{M}$ ) 


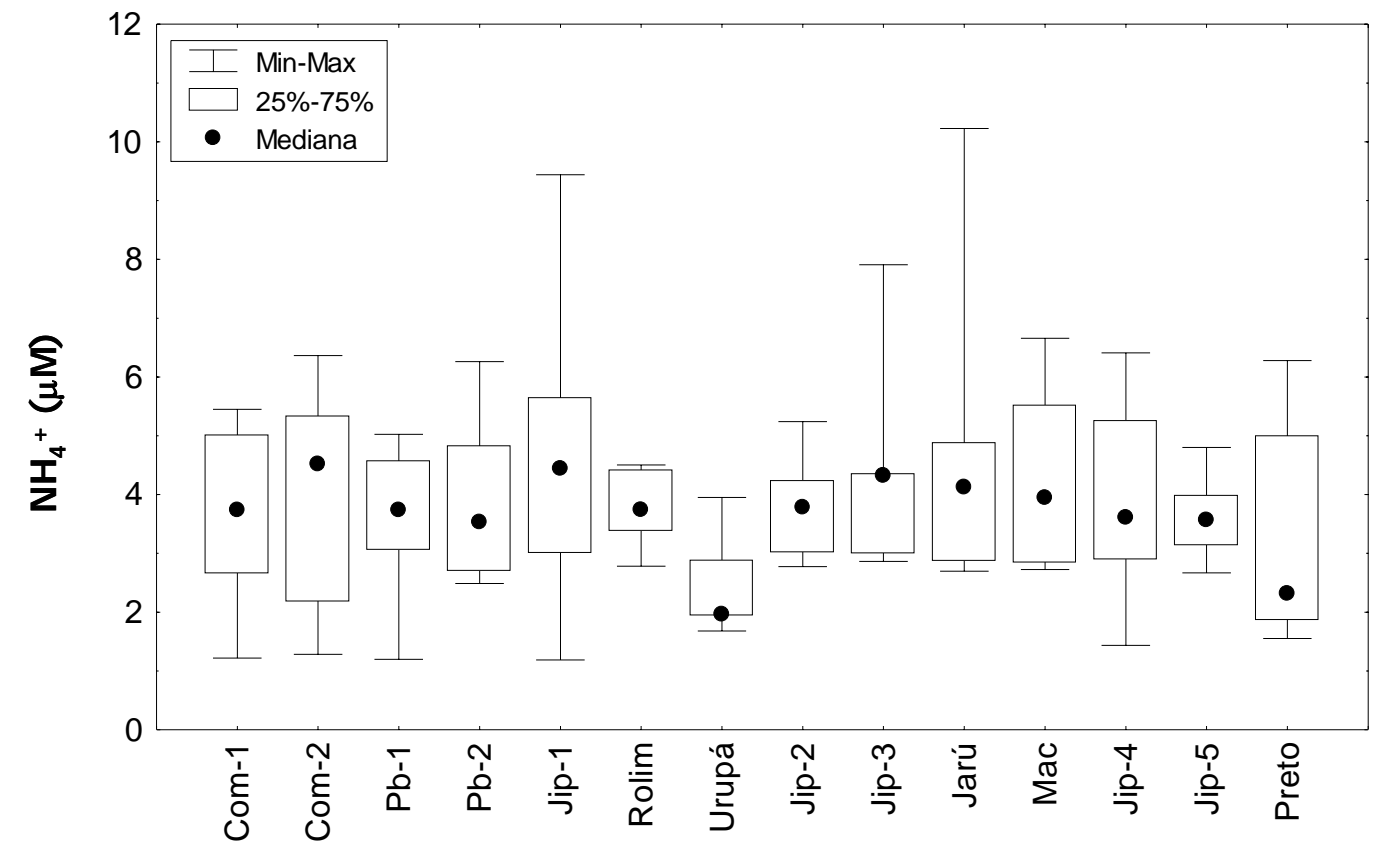

Figura 18 - Variação espacial das concentrações de $\mathrm{NH}_{4}{ }^{+}$nas águas dos rios da bacia do Ji-Paraná (valores em $\mu \mathrm{M}$ )

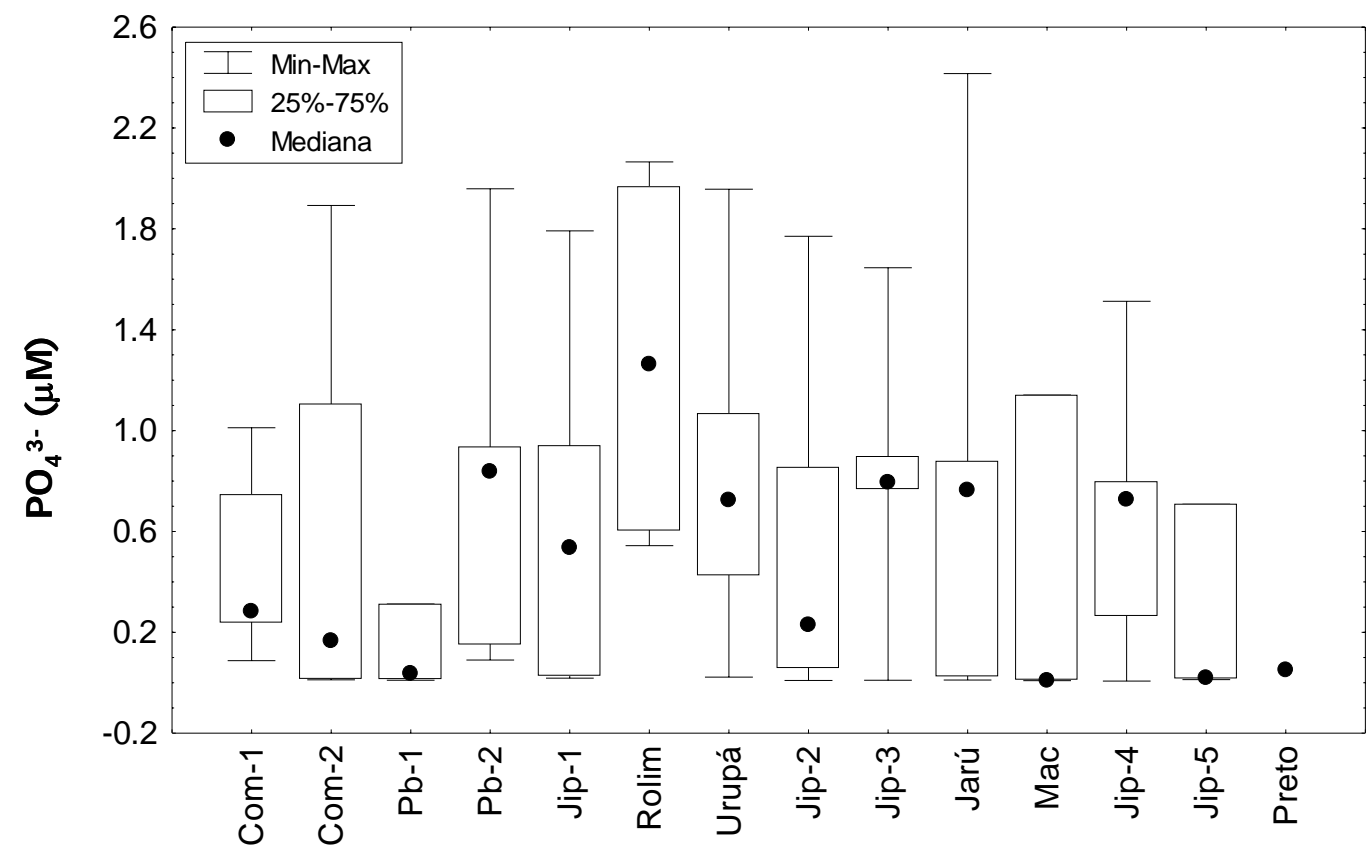

Figura 19 - Variação espacial das concentrações de $\mathrm{PO}_{4}{ }^{3-}$ nas águas dos rios da bacia do Ji-Paraná (valores em $\mu \mathrm{M}$ ) 
Urupá e Jarú, com a presença de rochas mais jovens (basaltos, gabros) resultam em águas mais ricas em sais dissolvidos. O oposto se observa nas bacias dos rios Comemoração, Pimenta Bueno, Machadinho e Preto, onde rochas sedimentares (arenitos, argilitos e conglomerados) estão associadas a águas pobres em íons.

A princípio, isto poderia indicar que os padrões observados resultam de características naturais. Entretanto, os solos mais férteis também estão associados aos maiores percentuais de pastagens nas respectivas sub-bacias (Ballester et al., 2003). Portanto, é possível, também, que resultem de alterações no uso e cobertura dos solos ou, mesmo, de uma combinação dos dois fatores, com uma magnificação dos processos de lixiviação nas pastagens (Krusche et al., no prelo; Kaufmann, 1998). Porém, as concentrações mais elevadas de $\mathrm{C}, \mathrm{N}$ e $\mathrm{P}$ nos rios próximos a grandes centros urbanos, ou com densidade elevada de rebanho bovino, são um forte indício de que o impacto antropogênico nesta bacia de drenagem já começa a alterar a biogeoquímica de seus rios.

\subsection{Variações Sazonais}

Para identificar as variações sazonais dos principais elementos dissolvidos nas águas dos rios da bacia do Ji-Paraná relacionamos, inicialmente, a condutividade elétrica com a descarga, tendo em vista que a primeira apresentou o mesmo padrão de variação espacial que as concentrações dos íons maiores (com exceção do $\mathrm{SO}_{4}{ }^{2-}$ ). Na nascente do rio Pimenta Bueno, nos rios Comemoração, Machadinho e Preto, e nos dois primeiros pontos coletados no canal principal do rio Ji-Paraná (JIP-1 e JIP-2), as maiores concentrações de solutos ocorreram no período de maiores descargas (Figura 20), com correlações positivas e estatisticamente significativas $(\mathrm{p}<0,05)$. Estes rios estão localizados nas regiões que apresentam os solos menos férteis da bacia (Figura 3), descartando desta forma, a possibilidade de controle da química de suas águas por processos de intemperismo, uma vez que os solos muito intemperizados e lixiviados não possuem a capacidade de fornecer os solutos durante o período de menores vazões, quando os rios são alimentados pela água subterrânea e o intemperismo químico é 


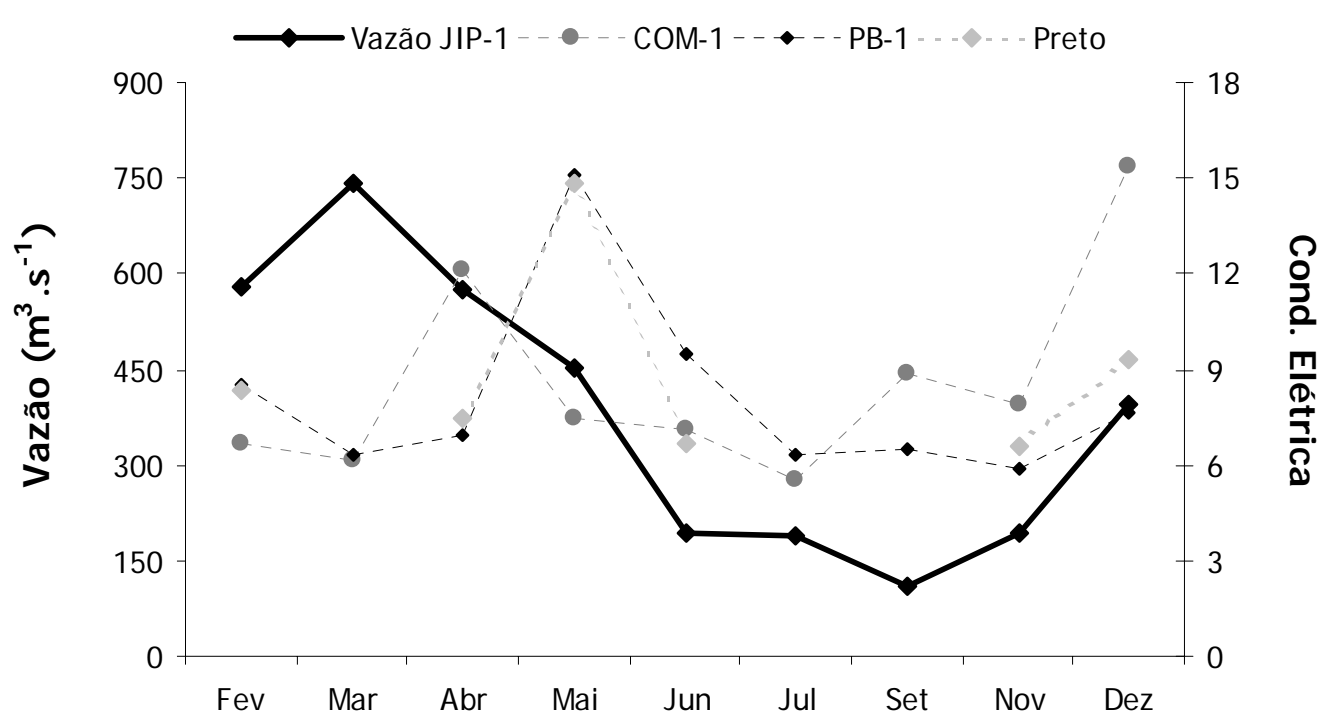

Figura 20 - Relação entre Vazão e Condutividade Elétrica para os rios mais empobrecidos em íons dissolvidos na bacia do Ji-Paraná

máximo (Lesack, 1993; Markewitz, 2001).

Considerando outras características destes rios, como as baixas concentrações de solutos, e maiores concentrações de $\mathrm{Na}^{+}$em relação a $\mathrm{Ca}^{2+}$, podemos classificá-los de acordo com o modelo proposto por Gibbs (1970), como controlados por precipitação atmosférica. Segundo Markewitz et al. (2001), estes tipos de rios tendem a apresentar suas maiores concentrações de elementos dissolvidos no período de maiores vazões, em função do carreamento de sais pelas águas que percolam os solos e chegam até os rios.

Por outro lado, os rios Rolim de Moura, Urupá e Jarú apresentaram um padrão inverso (Figura 21), semelhante àquele encontrado em rios de ambientes temperados, onde a relação entre a concentração de íons dissolvidos e a descarga é inversa (Feller \& Kimmins, 1979; Lesack, 1993). O principal mecanismo controlador da química das águas desses rios é o intemperismo de rochas (Gibbs, 1970), que se reflete em maiores concentrações de íons nos períodos de menores descargas. Isto é função do maior tempo de residência de suas águas subterrâneas com o substrato litológico no período de estiagem, o que maximiza o intemperismo químico e as torna relativamente mais ricas em sais. No período chuvoso, observa-se uma diluição nas concentrações, devido ao 


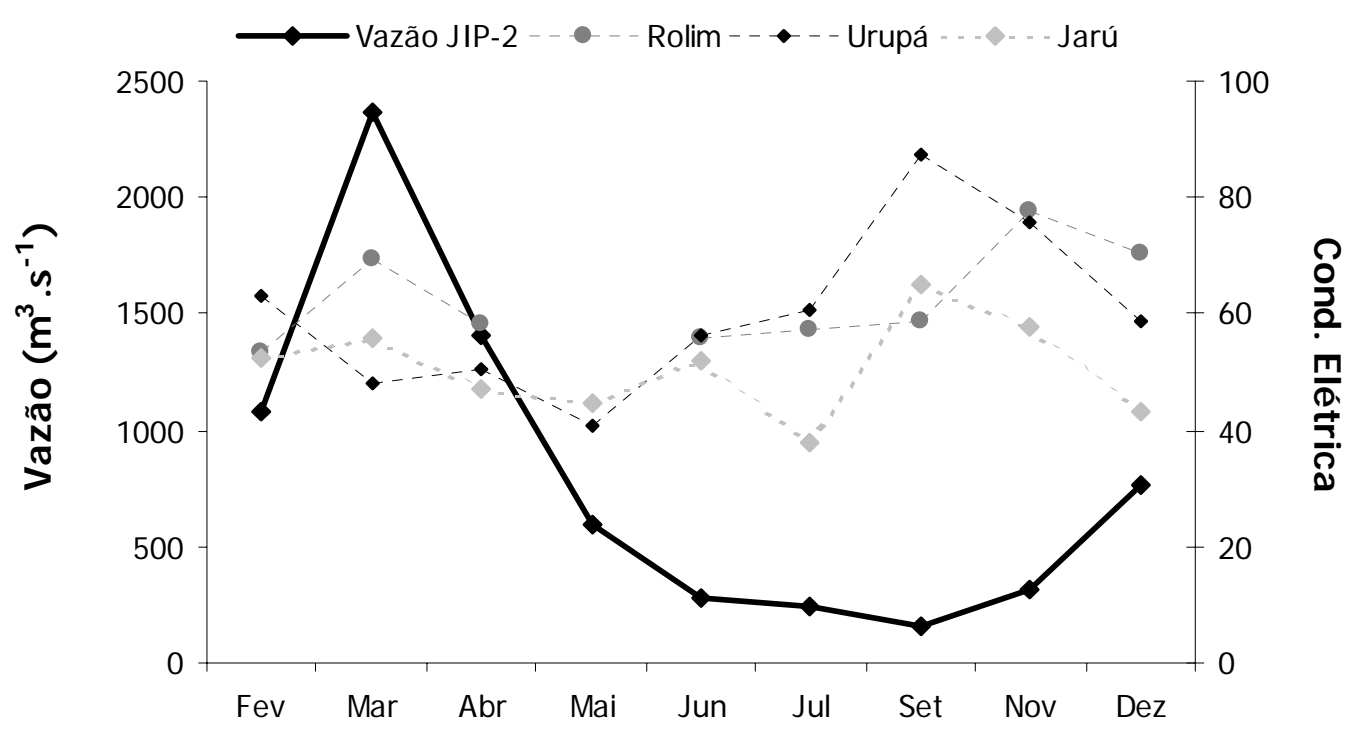

Figura 21 - Relação entre Vazão e Condutividade Elétrica para os rios mais enriquecidos em íons dissolvidos na bacia do Ji-Paraná

maior aporte da água de chuva, menos ricas em sais (Drever, 1997). Este mecanismo não ocorre nos rios anteriormente citados (Comemoração, Pimenta Bueno, Machadinho e Preto) porque, com um substrato litológico muito intemperizado, mesmo que haja um maior tempo de retenção, não há sais suficientes para que o intemperismo aumente as concentrações em solução (Markewitz et al., 2001).

Os demais pontos coletados no rio Ji-Paraná e o ponto no Pimenta Bueno próximo da confluência com o Comemoração não apresentaram diferenças estatísticas significativas $(p<0,05)$ entre os períodos do ano hidrológico. Isto pode ser decorrência dos processos de mistura de águas de origens distintas, conforme indicado anteriormente pelo diagramas ternário (Figura 7). No rio Pimenta Bueno, por exemplo, um padrão existente nas nascentes combina-se a outro oposto ao longo do percurso, anulando-se no setor mais à jusante. No rio Ji-Paraná, o aporte relativo de águas que se apresentam mais enriquecidas em sais em épocas opostas da hidrógrafa produz resultado similar.

Os sedimentos em suspensão apresentaram diferenças estatisticamente significativa entre os períodos de cheia e seca $(p<0,01)$, com as maiores concentrações sendo observadas no período de maiores vazões (Figura 22). Esta característica, comum a outros rios, pode ser explicada pelo aumento da erosão nestes períodos. Entretanto, na 


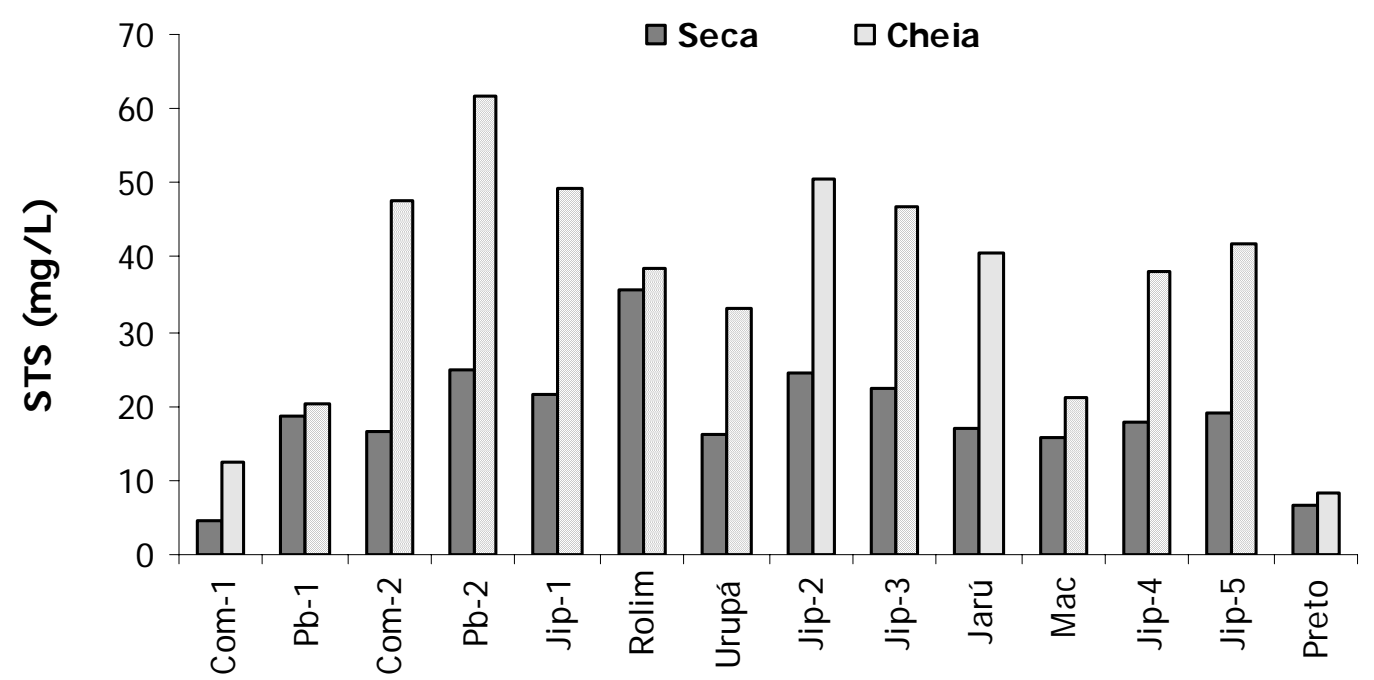

Figura 22 - Variação temporal das concentrações de Sedimentos Totais em Suspensão nas águas dos rios da bacia do Ji-Paraná (valores em mg.. ${ }^{-1}$ )

bacia do rio Ji-Paraná observou-se que as maiores concentrações deste ocorreram nas sub-bacias onde predominam pastagens, provavelmente como resultado da magnificação dos processos erosivos decorrentes deste tipo de uso da terra.

As maiores concentrações de NID foram encontradas no período de menores vazões (Figura 23). Esta característica pode estar relacionada com a disponibilidade deste nutriente na água subterrânea, oriundo da decomposição da matéria orgânica no solo, que proporciona um aporte constante do mesmo. No período chuvoso, observa-se uma diluição destas concentrações, com a entrada da água de chuva, fato já observado em outros rios da Amazônia (Davidson et al., 2003).

O fósforo inorgânico solúvel apresentou suas maiores concentrações na região central da bacia. Contudo, ao contrário do NID, suas maiores concentrações ocorreram no período de maiores vazões (Figura 24). Como este elemento possui um ciclo quase que exclusivamente sedimentar este fato pode ser resultado do aumento da erosão no período, que resulta no carreamento de maiores quantidades de $\mathrm{P}$ nas formas particulada ou adsorvida, sujeitas, respectivamente, à solubilização ou desorção no meio aquoso. 


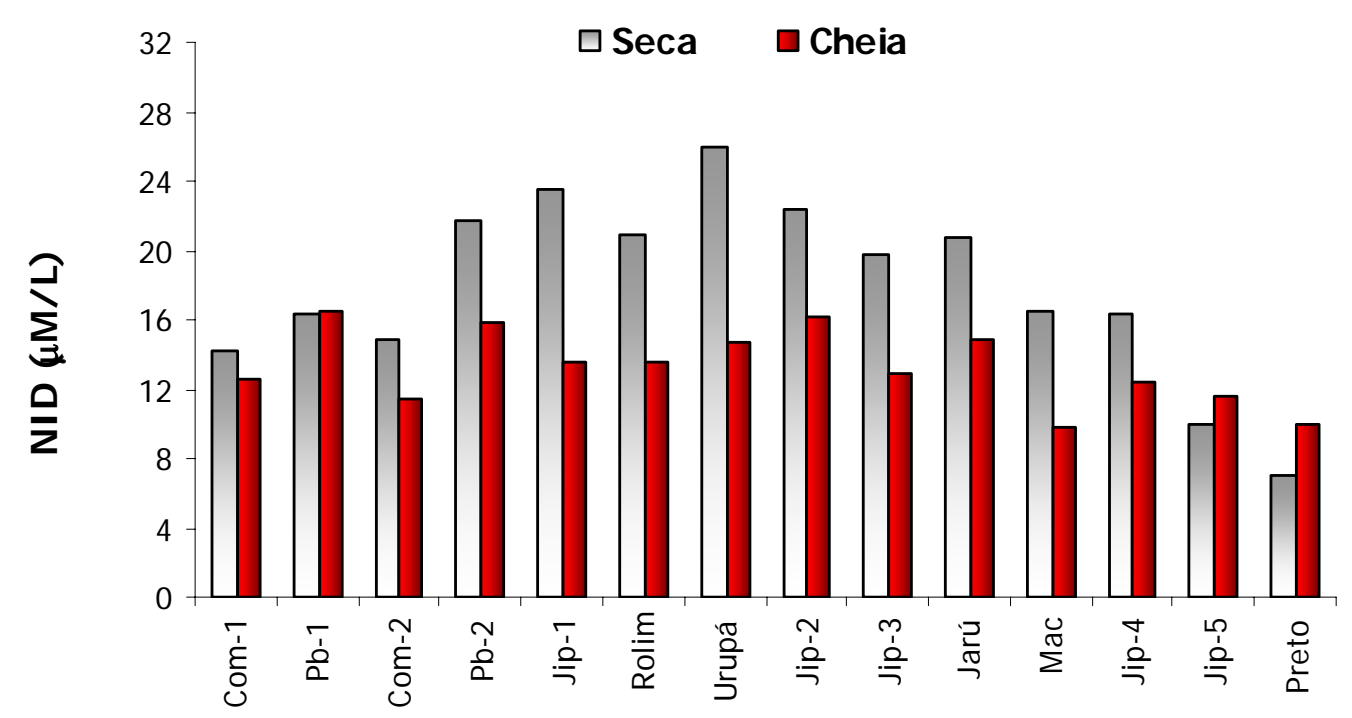

Figura 23 - Variação sazonal do Nitrogênio Inorgânico Dissolvido nas águas dos rios da bacia do Ji-Paraná (valores em $\mu \mathrm{M}$ )

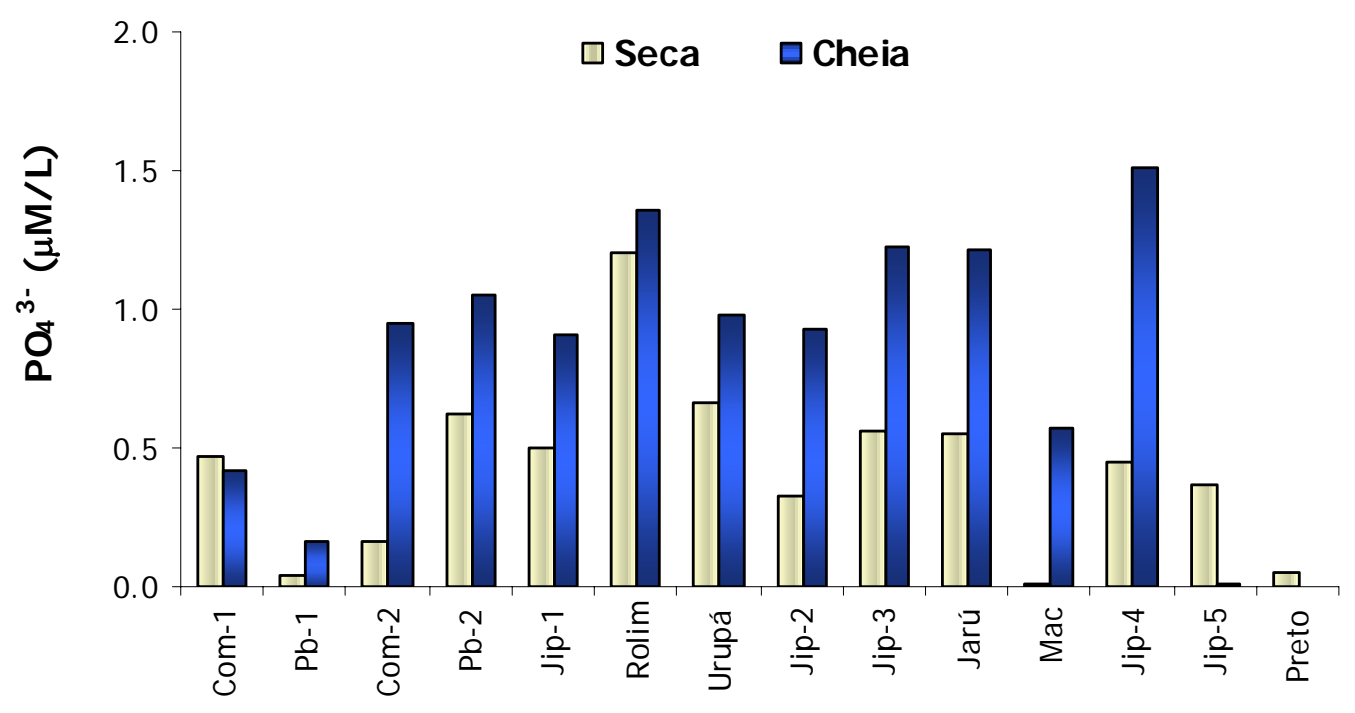

Figura 24 - Variação temporal das concentrações de $\mathrm{PO}_{4}{ }^{3-}$ nas águas dos rios da bacia do Ji-Paraná (valores em $\mu \mathrm{M}$ ) 


\section{CONCLUSÕES}

As variações espaciais e sazonais dos íons dissolvidos nas águas da bacia do rio Ji-Paraná apresentaram distintos padrões, com uma forte correlação com características naturais da mesma, como fertilidade dos solos e geologia, sendo que:

a) as maiores concentrações ocorreram nos pontos localizados na região central da bacia, onde predominam os solos mais férteis, e no período de menores vazões, indicando que o intemperismo de rochas é o principal mecanismo controlador da química destas águas superficiais, conforme observado em muitos rios de regiões temperadas;

b) as menores concentrações foram observadas nas regiões com os solos menos férteis, no período de maiores descargas, indicando que os íons dissolvidos possam ser provenientes de processos de percolação e lixiviação das camadas mais superficiais destes solos sobre rochas muito intemperizadas, conforme observado por outros autores (Markewitz, 2001).

Entretanto, além destas relações com as características físicas (fertilidade e geologia), tal variabilidade na química das águas também pode estar associada com os tipos de uso/cobertura do solo, tendo em vista que as áreas que apresentam solos mais férteis possuem também os maiores percentuais de pastagens nas suas sub-bacias.

Apesar destes dados não permitirem o isolamento dos principais fatores controladores (naturais $\mathrm{X}$ antropogênicos) da química destas águas, as maiores concentrações de nutrientes $\mathrm{C}$, $\mathrm{N}$ e $\mathrm{P}$ nas regiões mais alteradas pela presença humana são indícios de que tais mudanças já estejam se refletindo na biogeoquímica destes rios. 


\section{REFERÊNCIAS BIBLIOGRÁFICAS}

BALLESTER, M.V.R.; VICTORIA, D.D.C.; KRUSCHE, A.V.; COBURN, R.; VICTORIA, R.L.; RICHEY, J.E.; LOGSDON, M.G.; MAYORGA, E.; MATRICARDI, E. A remote sensing/GIS-based physical template to understand the biogeochemistry of the Ji-Paraná river basin (Western Amazonia). Remote Sensing of Environment, v.87, n.1, p.429-445, 2003.

BASTOS, T.X.; DINIZ, T.A. Avaliação do clima do Estado de Rondônia para desenvolvimento agrícola. Boletim de Pesquisa, Embrapa - Centro de Pesquisa Agropecuária do Trópico Úmido (CPATU), v. 44, 1982. 28p.

BIGGS, T.W.; DUNNE, T.; DOMINGUES, T.F.; MARTINELLI, L.A. Relative influence of natural watershed properties and human disturbance on stream solute concentrations in the southwestern Brazilian Amazon basin. Water Resources Research, v.38, n.8, 2002.

BRASIL. Monitoring of the Brazilian Amazon forest by satellite 1999-2000. São José dos Campos/SP: INPE, 24p, 2002.

BUSH, M.B. Amazonian conservation in a changing world. Biological Conservation, v.76, n.3, p.219-228, 1996.

COLLINS, R.; JENKINS, A. The impact of agricultural land use on stream chemistry in the middle hills of the Himalayas, Nepal. Journal of Hydrology, v.185, n.1/4, p.7186, Nov 1, 1996.

DALE, V.H.; PEARSON, S.M.; OFFERMAN, H.L.; ONEILL, R.V. Relating patterns of land-use change to faunal biodiversity in the central Amazon. Conservation Biology, v.8, n.4, p.1027-1036, 1994.

DAVIDSON, E.A.; NEILL, C.; KRUSCHE, A.V.; MARKEWITZ, D.; FIGUEIREDO, R.D.O.; BALLESTER, M.V. Loss of nutrients from terrestrial ecosystems to streams and the atmosphere following land use change in Amazonia. In: CHAPMAN CONFERENCE ON ECOSYSTEM INTERACTION WITH LAND USE CHANGE, Santa Fe, New Mexico, 14-18 June 2003. S. ed., 2003. 1 v. 
DIONEX. Manuals \& Literature (Compact Disc). Revision 08. Sunnyvale, CA. 2000.

DOWNING, J.A.; MCCLAIN, M.; TWILLEY, R.; MELACK, J.M.; ELSER, J.; RABALAIS, N.N.; LEWIS, W.M.; TURNER, R.E.; CORREDOR, J.; SOTO, D.; YANEZ-ARANCIBIA, A.; KOPASKA, J.A.; HOWARTH, R.W. The impact of accelerating land-use change on the $\mathrm{N}$-cycle of tropical aquatic ecosystems: Current conditions and projected changes. Biogeochemistry, v.46, n.1/3, p.109-148, 1999.

DREVER, J.I. The Geochemistry of Natural Waters. 3. ed. New Jersey: Prentice-Hall, 1997. 436p.

EDEN, M.J. Ecology and land-development - Case of Amazonian rainforest. Transactions of the Institute of British Geographers, v.3, n.4, p.444-463, 1978.

ELSENBEER, H.; NEWTON, B.E.; DUNNE, T.; DE MORAES, J.M. Soil hydraulic conductivities of latosols under pasture, forest and teak in Rondonia, Brazil. Hydrological Processes, v.13, n.9, p.1417-1422, Jun 30, 1999.

Empresa Brasileira de Pesquisa Agropecuária. Mapa de levantamento de reconhecimento de média intenside dos solos do Estado de Rondônia. Mapas 73, 74, 75 e 76. CEPA, 1983.

Empresa Brasileira de Pesquisa Agropecuária. Sistema Brasileiro de Classificação de Solos. Brasília: Embrapa Produção de Informação, 1999. 412p.

FEARNSIDE, P.M. Biodiversity as an environmental service in Brazil's Amazonian forests: risks, value and conservation. Environmental Conservation, v.26, n.4, p.305-321, Dec, 1999.

FEDERAL INTERAGENCY SEDIMENTATION PROJECT. A study of methods used in measurement and analysis of sediment load in reservoirs. Report NN, 2000. 29p.

FELLER, M.C.; KIMMINS, J.P. Chemical Characteristics of Small Streams near Haney in Southwestern British-Columbia. Water Resources Research, v.15, n.2, p.247258, 1979.

GASH, J.H.C.; NOBRE, C.A.; ROBERTS, J.M.; VICTORIA, R.L., (Ed.). Amazonian Deforestation and Climate: S.L.: John Wiley, 1996. 638p.

GIARDINA, C.P.; SANFORD, R.L.; DOCKERSMITH, I.C.; JARAMILLO, V.J. The effects of slash burning on ecosystem nutrients during the land preparation phase of shifting cultivation. Plant and Soil, v.220, n.1/2, p.247-260, 2000. 
GIBBS, R.J. Mechanisms controlling world water chemistry. Science, v.170, n.3962, p.1088-1090, 1970.

GIBBS, R.J. Water chemistry of Amazon river. Geochimica Et Cosmochimica Acta, v.36, n.9, p.1061-1066, 1972.

HAUER, F.R.; LAMBERTI, G.A. Methods in Stream Ecology. San Diego: Academic Press, 1996. 674p.

HERPIN, U.; CERRI, C.C.; CARVALHO, M.C.S.; MARKERT, B.; ENZWEILER, J.; FRIESE, K.; BREULMANN, G. Biogeochemical dynamics following land use change from forest to pasture in a humid tropical area (Rondonia, Brazil): a multielement approach by means of XRF-spectroscopy. Science of the Total Environment, v.286, n.1/3, p.97-109, Mar 8, 2002.

HERRERA, R.; JORDAN, C.F.; KLINGE, H.; MEDINA, E. Amazon ecosystems - their structure and functioning with particular emphasis on nutrients. Interciencia, v.3, n.4, p.223-232, 1978.

HIRAOKA, M. The Development of Amazonia. Geographical Review, v.72, n.1, p.9498, 1982.

KAUFFMAN, J.B.; CUMMINGS, D.L.; WARD, D.E. Fire in the Brazilian Amazon 2. Biomass, nutrient pools and losses in cattle pastures. Oecologia, v.113, n.3, p.415427, Feb, 1998.

KLEINMAN, P.J.A.; PIMENTEL, D.; BRYANT, R.B. The Ecological sustainability of slash-and-burn agriculture. Agriculture Ecosystems \& Environment, v.52, n.2/3, p.235-249, Feb, 1995.

KRISHNASWAMY, J.; RICHTER, D.D. Properties of advanced weathering-stage soils in tropical forests and pastures. Soil Science Society of America Journal, v.66, n.1, p.244-253, Jan-feb, 2002.

KRUSCHE, A.V.; BALLESTER, M.V.R.; VICTORIA, R.L.; BERNARDES, M.C.; LEITE, N.K.; HANADA, L.; MARCONDES, R.; VICTORIA, D.C.; TOLEDO, M.A.; OMETTO, J.P.H.B.; MOREIRA, M.Z.; GOMES, B.M.; BOLSON, M.A.; NETO, S.G.; BONELLI, N.; DEEGAN, L; NEILL, C.; THOMAS, S.; AUFDENKAMPE, A.; RICHEY, J.E. As mudanças no uso da terra e a biogeoquímica dos corpos d’água na Amazônia. Acta Amazônica. (No prelo). 
LAMBIN, E.F.; TURNER, B.L.; GEIST, H.J.; AGBOLA, S.B.; ANGELSEN, A.; BRUCE, J.W.; COOMES, O.T.; DIRZO, R.; FISCHER, G.; FOLKE, C.; GEORGE, P.S.; HOMEWOOD, K.; IMBERNON, J.; LEEMANS, R.; LI, X.B.; MORAN, E.F.; MORTIMORE, M.; RAMAKRISHNAN, P.S.; RICHARDS, J.F.; SKANES, H.; STEFFEN, W.; STONE, G.D.; SVEDIN, U.; VELDKAMP, T.A.; VOGEL, C.; XU, J.C. The causes of land-use and land-cover change: moving beyond the myths. Global Environmental Change-Human and Policy Dimensions, v.11, n.4, p.261269, Dec, 2001.

LESACK, L.F.W. Export of nutrients and major ionic solutes from a rain-forest catchment in the central Amazon basin. Water Resources Research, v.29, n.3, p.743-758, Mar, 1993.

LIKENS, G.E.; BORMANN, F.H. Biogeochemistry of a forested ecosystem. 2. ed. New York: Springer-Verlag, 1995. 159p.

MARKEWITZ, D.; DAVIDSON, E.A.; FIGUEIREDO, R.D.O.; VICTORIA, R.L.; KRUSCHE, A.V. Control of cation concentrations in stream waters by surface soil processes in an Amazonian watershed. Nature, v.410, n.6830, p.802-805, Apr 12, 2001.

MCCLAIN, M.E.; RICHEY, J.E.; PIMENTEL, T.P. Groundwater nitrogen dynamics at the terrestrial-lotic interface of a small catchment in the central Amazon basin. Biogeochemistry, v.27, n.2, p.113-127, 1994.

MCGRATH, D.A.; SMITH, C.K.; GHOLZ, H.L.; OLIVEIRA, F.D. Effects of land-use change on soil nutrient dynamics in Amazonia. Ecosystems, v.4, n.7, p.625-645, Nov, 2001.

MELILLO, J.M.; HOUGHTON, R.A.; KICKLIGHTER, D.W.; MCGUIRE, A.D. Tropical deforestation and the global carbon budget. Annual Review of Energy and the Environment, v.21, p.293-310, 1996.

MOTULSKY, H. Intuitive bioestatistic. Oxford: Oxford University Press, 1995. 368p.

NEILL, C.; PICCOLO, M.C.; STEUDLER, P.A.; MELILLO, J.M.; FEIGL, B.J.; CERRI, C.C. Nitrogen dynamics in soils of forests and active pastures in the western Brazilian Amazon basin. Soil Biology \& Biochemistry, v.27, n.9, p.1167-1175, Sep, 1995.

NEILL, C.; DEEGAN, L.A.; THOMAS, S.M.; CERRI, C.C. Deforestation for pasture alters nitrogen and phosphorus in small Amazonian streams. Ecological Applications, v.11, n.6, p.1817-1828, 2001. 
OLTMAN, R.E.; BRAZIL. MINISTERIO DA MARINHA.; RIO DE JANEIRO. UNIVERSIDADE FEDERAL. Reconnaissance investigations of the discharge and water quality of the Amazon River. Washington: 1968, 16 p.

PEDLOWSKI, M.A.; DALE, V.H.; MATRICARDI, E.A.T.; DA SILVA, E.P. Patterns and impacts of deforestation in Rondonia, Brazil. Landscape and Urban Planning, v.38, n.3/4, p.149-157, 1997.

PEKAROVA, P.; PEKAR, J. The impact of land use on stream water quality in Slovakia. Journal of Hydrology, v.180, n.1/4, p.333-350, 1996.

PUTZ, F.E.; BLATE, G.M.; REDFORD, K.H.; FIMBEL, R.; ROBINSON, J. Tropical forest management and conservation of biodiversity: an overview. Conservation Biology, v.15, n.1, p.7-20, Feb, 2001.

REINERS, W.A.; BOUWMAN, A.F.; PARSONS, W.F.J.; KELLER, M. Tropical rainforest conversion to pasture - Changes in vegetation and soil properties. Ecological Applications, v.4, n.2, p.363-377, May, 1994.

RHODES, A.L.; NEWTON, R.M.; PUFALL, A. Influences of land use on water quality of a diverse new England watershed. Environmental Science \& Technology, v.35, n.18, p.3640-3645, Sep 15, 2001.

RICHTER, D.D.; BABBAR, L.I. Soil diversity in the tropics. Advances in Ecological Research, v.21, p.315-389, 1991.

RICHEY, J.E.; HEDGES, J.I.; DEVOL, A.H.; QUAY, P.D.; VICTORIA, R.; MARTINELLI, L.; FORSBERG, B.R. Biogeochemistry of carbon in the Amazon river. Limnology and Oceanography, v.35, n.2, p.352-371, Mar, 1990.

RICHEY, J.E.; WILHELM, S.R.; MCCLAIN, M.E.; VICTORIA, R.L.; MELACK, J.M.; LIMA, C.A. Organic matter and nutrient dynamics in river corridors of the Amazon basin and their response to anthropogenic change. Ciência e Cultura Journal of the Brazilian Association for the Advancement of Science, v.49, n.1/2, p.98-110, 1997.

RONDÔNIA, Governo do Estado de. Diagnóstico Sócio - Econômico do Estado de Rondônia. 2002. 1v.

SALATI, E.; VICTORIA, R.L.; MARTINELLI, L.A.; RICHEY, J.E. Deforestation and its role in possible changes in the Brazilian Amazon. In: DEFRIES, R.S.; MALONE, T.F. (Ed.). Global Change and Our Common Future: Papers from a Forum. Washington, D.C.: National Academy Press, 1989. p.228. 
SCANDOLARA, J.E.; RIZZOTO, G.J.; BAHIA, R.B.C.; QUADROS, M.L.E.S.; SILVA, C.R.; AMORIM, J.L. Geologia do Estado de Rondônia. Porto Velho: Companhia de Pesquisa de Recursos Minerais, 1998. 66p.

SIOLI, H. The Amazon: Limnology and landscape ecology of a mighty tropical river and its basin. Dordrecht, the Netherlands: Dr. W. Junk Pub, 1984. 763p. (Monographiae Biologica).

STALLARD, R.F.; EDMOND, J.M. Geochemistry of the Amazon .2. The influence of geology and weathering environment on the dissolved-load. Journal of Geophysical Research-Oceans and Atmospheres, v.88, n.NC14, p.9671-9688, 1983.

STUMM, W.; MORGAN, J.J. Aquatic Chemistry. 3. ed. New York: John Wiley, 1996, $1040 \mathrm{p}$.

TINKER, P.B.; INGRAM, J.S.I.; STRUWE, S. Effects of slash-and-burn agriculture and deforestation on climate change. Agriculture Ecosystems \& Environment, v.58, n.1, p.13-22, Jun, 1996.

UHL, C.; JORDAN, C.F. Succession and nutrient dynamics following forest cutting and burning in Amazonia. Ecology, v.65, n.5, p.1476-1490, 1984.

WALKER, R.; HOMMA, A.K.O. Land use and land cover dynamics in the Brazilian Amazon: An overview. Ecological Economics, v.18, n.1, p.67-80, Jul, 1996.

WILLIAMS, M.R.; MELACK, J.M. Solute export from forested and partially deforested catchments in the central Amazon. Biogeochemistry, v.38, n.1, p.67-102, Jul, 1997.

ZAR, J.H. Biostatistical analysis. 2. ed. New Jersey: Prentice-Hall. 1984. 718p. 